\title{
Revisiting IS business value research: what we already know, what we still need to know, and how we can get there
}

\section{Guido Schryen \\ Institute of Management Information Systems, University of Regensburg, Regensburg, Germany}

Correspondence: G. Schryen, Institute of Management Information Systems, University of Regensburg,

Universitätsstraße 31, Regensburg 93053, Germany.

Tel: 49941943 5634;

Fax: 49941943 5635;

E-mail: guido.schryen@ wiwi.uni-regensburg.de
Received: 24 September 2009

Revised: 22 March 2010

2nd Revision: 6 December 2010

3rd Revision: 29 July 2011

4th Revision: 5 February 2012

5th Revision: 24 April 2012

6th Revision: 10 June 2012

Accepted: 29 August 2012

\begin{abstract}
The business value of investments in Information Systems (IS) has been, and is predicted to remain, one of the major research topics for IS researchers. While the vast majority of research papers on IS business value find empirical evidence in favour of both the operational and strategic relevance of IS, the fundamental question of the causal relationship between IS investments and business value remains partly unexplained. Three research tasks are essential requisites on the path towards addressing this epistemological question: the synthesis of existing knowledge, the identification of a lack of knowledge and the proposition of paths for closing the knowledge gaps. This paper considers each of these tasks. Research findings include that correlations between IS investments and productivity vary widely among companies and that the mismeasurement of IS investment impact may be rooted in delayed effects. Key limitations of current research are based on the ambiguity and fuzziness of IS business value, the neglected disaggregation of IS investments, and the unexplained process of creating internal and competitive value. Addressing the limitations we suggest research paths, such as the identification of synergy opportunities of IS assets, and the explanation of relationships between IS innovation and change in IS capabilities.
\end{abstract}

European Journal of Information Systems (2013) 22, 139-169.

doi:I0.1057/ejis.2012.45; published online 13 November 2012

Keywords: IS business value; IS research framework; IS impact; IS value; research agenda; literature review

\section{Introduction}

The business value of investments in Information Systems (IS) has been, and is predicted to remain, one of the major research topics for IS researchers (Dehning et al, 2004; Roztocki \& Weistroffer, 2008). While only a few, mostly early studies (Dos Santos et al, 1993; West \& Courtney, 1993; Hitt \& Brynjolfsson, 1996; Rai et al, 1997; Im et al, 2001) doubt the economic power of IS, the vast majority of research papers on IS business value (e.g. (Dedrick et al, 2003; Dehning et al, 2003, 2008; Peslak, 2003; Santhanam \& Hartono, 2003; Swierczek \& Shrestha, 2003; Mahmood \& Mann, 2005; Zhang, 2005; Shin, 2006; Lin \& Shao, 2006a; Aral et al, 2007; Beccalli, 2007; Neirotti \& Paolucci, 2007; Wan et al, 2007; Kohli \& Grover, 2008; Kim et al, 2009; Ramirez et al, 2010; Han et al, 2011; Kim \& Mithas, 2011; Lee et al, 2011)) find empirical evidence and theoretical arguments in favour of both the operational and strategic relevance of IS. The prominent, but non-academic Harvard Business article by Carr (2003), entitled 'IT doesn't matter', has also been refuted (Schrage, 2003; 
DeJarnett et al, 2004). However, as Baker et al (2008) argue, the fundamental question of the causal relationship between IS investments and business value remains partly unexplained. In addition, new IS and new IS phenomena lead to more questions over time that require addressing. IS researchers have not fully managed to identify and explain the economic relevance of IS (Fink, 2011) so that business executives and researchers continue to question the value of IS investments (Kohli \& Grover, 2008). However, finding an answer to this question is regarded as fundamental to the contribution of the IS discipline (Agarwal \& Lucas, 2005).

Despite this epistemological deficiency in IS business value research, statistics on papers published in pertinent academic outlets show that after a publication peak in 2000 the numbers of published articles on IS business value declined (see Figure A1 in Appendix A). In particular, the journals Management Information Systems Quarterly (MISQ), Information Systems Research (ISR), Journal of Management Information Systems (JMIS) and European Journal of Information Systems (EJIS) have published only 10 articles on IS business value since 2005. We hypothesise that this decreasing attention to IS business value is not rooted in any declining interest on the part of the editors and reviewers of these journals, but is based on the declining activities of researchers in this field. In order to reactivate researchers' interest and activities in the central field of IS business value, this paper provides a fresh perspective on the question of how IS investments create business value.

Three research tasks are essential requisites on the path towards answering this question and strengthening the role of IS (business value) research: (1) Synthesis of knowledge (what do we know?) (2) Identification of lack of knowledge (what do we still need to know?) (3) Proposition of paths for closing the knowledge gap (how can we get there?). While many research articles, including literature reviews, address task 1 , only few address task 2 , and we rarely find contributions like those of Soh \& Markus (1995) and Kohli \& Grover (2008), which are dedicated to task 3. This paper pursues the idea that all three research tasks should be embedded into one logical flow. Consequently, its contribution is threefold: it provides a synthesis of key research findings, it identifies gaps in research, and it shows paths for overcoming the current research limitations by providing a research agenda.

The remainder of this paper is structured as follows: The next section frames IS business value research, as it is understood in this work. Subsequently, we synthesise key research findings before we identify research gaps. This is followed by the presentation of a detailed agenda for future IS business value research. Then we discuss the potential for further research and present concluding remarks.

\section{IS business value research}

\section{Information systems}

The academic field of IS research is terminologically pervaded with syntactically similar notions, such as 'information system (IS)', 'information technology (IT)', and 'information and communication technology (ICT)'. These notions often lack any precise semantic definition and differentiation, and they are often also based on different understandings. Reviewing articles published in Information Systems Research, Orlikowski \& Iacono (2001) find that the 'IT artefact' has not been theorised, and is widely interpreted depending on the specific research context. Having reviewed more than 300 papers related to IS business value, we find that this problem still exists. For example, only very few papers make explicit how they define their research object. The notional fuzziness and heterogeneous semantics in literature are not surprising, because the IS discipline does not yet provide a broadly accepted or even standardised terminology. For example, there are only few glossaries available (ITAA, 1996; CNSS, 2006; ATIS, 2007), which even differ in their respective definitions of 'IS' and 'IT'. In this review, we adopt the 'holistic' view on IS, as described in the ATIS Telecom Glossary (Option 3): The entire infrastructure, organization, personnel, and components for the collection, processing, storage, transmission, display, dissemination, and disposition of information.

\section{IS business value}

Notions and scope A wide range of articles on IS offers a variety of notions and semantics regarding the economic consequences of IS investments. For example, early works use the notions 'value', 'benefit', 'outcome' or 'worth'. Berghout \& Renkema (1997), Engelbert (1991), Wiseman (1992) and Melville et al (2004) investigate the 'organizational performance', and Kohli \& Grover (2008) refer to value as the 'economic impact'. The IS discipline still lacks a consistent and widely accepted definition of IS business value $(\mathrm{Oz}, 2005$, p. 796). The variety in terminology not only mirrors notional inconsistencies, it also reflects different understandings (semantics) of how to operationalise the economic impact of IS. For example, a large subset of empirical studies analyses the relationship between IS investments and productivity (Brynjolfsson \& Hitt, 1996), 'Return on Sales' (Bharadwaj, 2000) or Tobin's q (Brynjolfsson \& Yang, 1999). Other studies stress that, beyond financial and non-financial measures, intangible assets can be affected, such as organisational capabilities (Kohli \& Grover, 2008) or strategic position (Irani, 2002). The discussion becomes even more complicated when researchers also distinguish between what the particular outcome of an IS investment is, and how this outcome is interpreted. For example, the interpretation of a particular outcome, such as a productivity gain, depends on the view of the particular evaluator (Engelbert, 1991; Sylla \& Wen, 2002), on what competitors have achieved (Dehning \& Richardson, 2002) and on what is finally done to exploit it (Alshawi et al, 2003). We use the aforementioned facets of IS business value to structure the presentation of the research findings. 
Level of examination Literature suggests using different levels to examine the economic impact of IS. One widely used classification distinguishes individual level, firm level, industry level and economy level (Bakos, 1987; Kauffman \& Weill, 1989; Brynjolfsson \& Yang, 1996; Devaraj \& Kohli, 2000; Chau et al, 2007). In addition, research can also focus on consumer surplus (Bakos, 1987; Brynjolfsson \& Yang, 1996; Devaraj \& Kohli, 2000).

The importance of taking the particular level of examination into account is stressed by Dehning \& Richardson (2002, p. 8) and also by Brynjolfsson (1993), who states that the usage of different levels even contributes to the explanation of the 'productivity paradox'. Consequently, we take the level of examination into account in the following synthesis of the research findings.

Object of evaluation Due to the holistic definition of IS, investigations of the economic impact of IS investments differ in their objects of evaluation. While some studies consider overall IS investments, others are more specialised and focus on particular IS assets, such as IT capital (Hitt \& Brynjolfsson, 1994; Barua et al, 1995), or IS personnel and training (Chatterjee et al, 2001; Mahmood \& Mann, 2005). Similar to the level of examination, differences in the object of evaluation are considered in our analysis of results.

Time of evaluation As Kohli \& Grover (2008) stress, research on IS value can be of ex ante and ex post nature. While the ex ante evaluation of IS value supports decision makers in answering the question as to which of the alternative IS investment(s) available will best achieve the organisation's goals or preferences, ex post research investigates the extent to which IS investments have actually created value. This paper focuses on the latter aspect only.

Definition of IS business value Drawing on the aforementioned multiple facets of IS research, we define:

IS business value is the impact of investments in particular IS assets on the multidimensional performance and capabilities of economic entities at various levels, complemented by the ultimate meaning of performance in the economic environment.

The ultimate meaning of performance gains and losses (outcome) refers to what is subsequently derived if the outcome is exploited. For example, the outcome of introducing a workflow management system may be that a business process can now be performed more quickly. The ultimate meaning of the outcome comes from what is done with the time saved, and it also depends on the extent to which competitors have speeded up their processes.

\section{Theoretical paradigms used in IS business value research}

Researchers have employed many theoretical paradigms when analysing the value that IS creates for organisations.
These include microeconomics, industrial organisation theory, socio-political paradigms, organisational behaviour theory, resource-based view (RBV) and decision theory (Hoogeveen \& Oppelland, 2002; Melville et al, 2004; Paré et al, 2008).

In the field of microeconomics, the theory of production (Brynjolfsson, 1993; Brynjolfsson \& Hitt, 1995; Lichtenberg, 1995; Brynjolfsson \& Yang, 1996; Dewan \& Min, 1997; Dedrick et al, 2003), growth accounting (Jorgenson \& Stiroh, 1999; Brynjolfsson \& Hitt, 2003), consumer theory (Brynjolfsson, 1996; Hitt \& Brynjolfsson, 1996) and option pricing theory (Benaroch \& Kauffman, 1999) have been employed. Industrial organisation theory has been adopted by researchers who have applied game theory (Belleflamme, 2001), agency theory and contract theory (Clemons \& Kleindorfer, 1992; Bakos \& Nault, 1997), and transaction cost theory (Clemons \& Row, 1991; Gurbaxani \& Whang, 1991). Researchers have used socio-political paradigms by applying the theory of embeddedness (Chatfield \& Yetton, 2000). Organisational behaviour theory was used by Devaraj \& Kohli (2000), and the RBV has been adopted in many studies (Clemons \& Row, 1991; Mata et al, 1995; Powell \& Dent-Micallef, 1997; Jarvenpaa \& Leidner, 1998; Bharadwaj, 2000; Caldeira \& Ward, 2003; Santhanam \& Hartono, 2003; Melville et al, 2004). Beyond the adoption of established theories, several researchers have also proposed new theories, prominent examples being the process theory of Soh \& Markus (1995), the processoriented framework of Mooney et al (1995), and the theoretical framework on the sustainability of competitive advantage rooted in IS use (Piccoli \& Ives, 2005).

We draw on some of the aforementioned theories in our research agenda in terms of suggesting theoretical foundations for research thrusts.

\section{Synthesising research findings}

The economic relevance of IS has been studied for many years and 12 years ago it had already attracted more than 1000 research papers (Bannister \& Remenyi, 2000). In order to cover this abundance of literature systematically, to synthesise key research findings and to identify research problems, we conducted a comprehensive literature search: We performed a title search in pertinent journal databases and also scanned the table of contents of pertinent journals, including MIS Quarterly, Information Systems Research, Management Science, Journal of Management Information Systems, Organization Science, among others (see Appendix B for details on the search process). The final body of literature considered in this study consists of more than 200 articles. Based on prior work (Schryen, 2010a,b), we also explored the following literature reviews on IS business value, which have been published since 1989 in peer-reviewed journals or peerreviewed conference proceedings: (Kauffman \& Weill, 1989; DeLone \& McLean, 1992; Brynjolfsson, 1993; Soh \& Markus, 1995; Brynjolfsson \& Yang, 1996; Sircar et al, 1998; Seddon et al, 1999; Bannister \& Remenyi, 2000; 
Chan, 2000; Devaraj \& Kohli, 2000; Dehning \& Richardson, 2002; Irani \& Love, 2002; Sylla \& Wen, 2002; Dedrick et al, 2003; Melville et al, 2004; Piccoli \& Ives, 2005; Chau et al, 2007; Wan et al, 2007; Kohli \& Grover, 2008; Paré et al, 2008).

Reviewing the large body of literature on IS business value research reveals that this field is dominated by

- empirical studies (Chen \& Hwang, 1991; Chan, 2000; Paré et al, 2008) and econometric approaches,

- the ex post perspective,

- the adoption of variance theories in contrast to process theories (Markus \& Robey, 1988; Soh \& Markus, 1995; Sircar et al, 1998; Paré et al, 2008),

- a firm-level perspective (Chau et al, 2007; Wan et al, 2007; Paré et al, 2008),

- the analysis of firm performance in terms of productivity, market performance and accounting performance, and the consideration of the complementary influence of contextual factors and lag effects.

In order to organise the presentation of prior research, we define and apply a new conceptual model, which is based on a synthesis of four prominent IS business value models (see Figure 1) proposed by Dedrick et al (2003), Dehning \& Richardson (2002), Melville et al (2004) and Soh \& Markus (1995). The advantage of drawing on these research models lies in their wide adoption by IS researchers, which allows us to map and assess the research findings of IS business value literature appropriately. Our approach of synthesising these models is not an attempt to unify (and simplify) different perspectives applied by researchers, but it pursues the aim to identify and present their shared understanding of IS business value. We argue that this synthesis is useful in guiding the presentation of key results in the IS business value literature.

The four models shown in Figure 1 show consensus with regard to the following basic insights:

1. The impact of IS investments can be assessed along numerous performance measures, which can be divided into process performance measures and firm/ organisational performance measures. The latter can be further divided into market measures and financial/ accounting measures. The impact of IS investments on firm performance is mediated through process performance.

2. The impact of IS investments on process performance and firm performance is affected by contextual/ environmental factors on the firm, industry and country levels.

3. IS investments and resulting assets can occur in different forms: they can consist of IT expenditures (hardware, software, technical infrastructure), human IS resources and IS management capabilities. IS investments are complemented with non-IS investments, and together they affect process performance.
There is also strong empirical evidence in the literature that the impact of IS investments also needs to account for substantial time lags, which can span a period of years (Brynjolfsson \& Hitt, 1998; Santhanam \& Hartono, 2003; Jain, 2005; Mahmood \& Mann, 2005). Synthesizing the aforementioned key insights leads to the model shown in Figure 2.

We now use this model to draw a condensed picture of what the literature has found in key research areas (see Table 1 for a summary of key findings).

\section{Performance measures}

One of the most important topics in the economic appraisal of IS investments is the question of what to measure. During the past 20 years, the body of literature on the economic appraisal of IS investments has grown enormously, and so has the number of economic measures investigated. For example, researchers have addressed productivity (Brynjolfsson \& Hitt, 1996, 2000), capacity utilisation and product quality (Barua et al, 1995; Thatcher \& Oliver, 2001; Thatcher \& Pingry, 2004b, 2007), customer satisfaction (Devaraj \& Kohli, 2000), production efficiency (Thatcher \& Oliver, 2001) and productive efficiency (Chen \& Lin, 2009; Lin, 2009), consumer welfare (Thatcher \& Pingry, 2004a, b; Thatcher \& Pingry, 2007), various profit ratios, such as 'Return on Assets' (Weill, 1992; Barua et al, 1995), and also market-oriented measures, such as Tobin's q (Bharadwaj et al, 1999; Brynjolfsson \& Yang, 1999).

The abundance of different aspects of IS success has been addressed by researchers who provide taxonomies to organise the diverse research studies (Ward, 1990; Seddon, 1997; Irani \& Love, 2002; Lee et al, 2008; Marthandan \& Tang, 2010). However, probably the most frequently adopted classification is proposed by DeLone \& McLean (1992), who provide a comprehensive IS success taxonomy that posits six dimensions: 'system quality', 'information quality', 'use', 'user satisfaction', 'individual impact' and 'organisational impact'. This model was extended by Seddon (1997), updated with minor refinements by DeLone \& McLean (2003), and also adopted in more recent research (DeLone \& McLean, 2004; Chau et al, 2007). Complementary to the taxonomy of DeLone \& McLean (1992), a simple and often applied classification distinguishes between (business) process performance and firm performance (Barua et al, 1995; Dehning \& Richardson, 2002; Melville et al, 2004). This process-oriented perspective has been widely adopted to show that the impact of IS investments on firm performance is intermediated by process performance (Barua et al, 1995; Mooney et al, 1995; Soh \& Markus, 1995; Shin, 1997; Dehning \& Richardson, 2002; Lee et al, 2004; Kim et al, 2006).

Summing up, both the DeLone and McLean model and its extensions, and the process/firm performance perspective are widely accepted and are deemed appropriate for the classification of performance measures. 


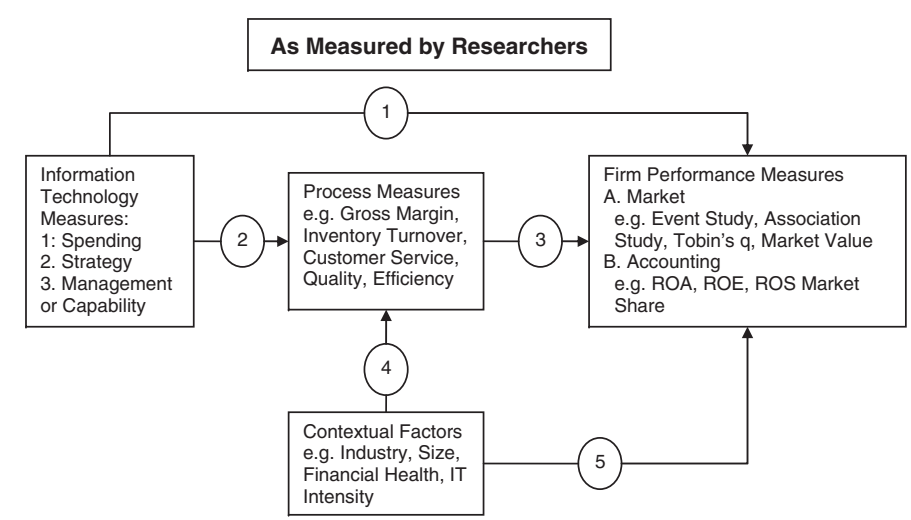

C

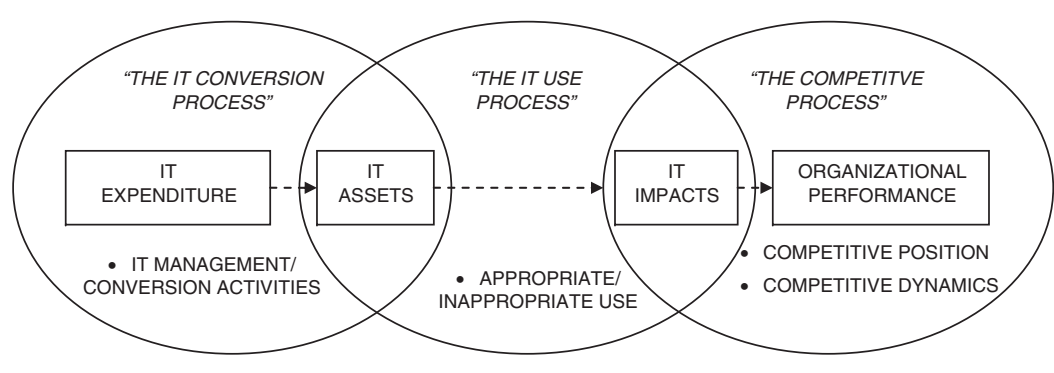

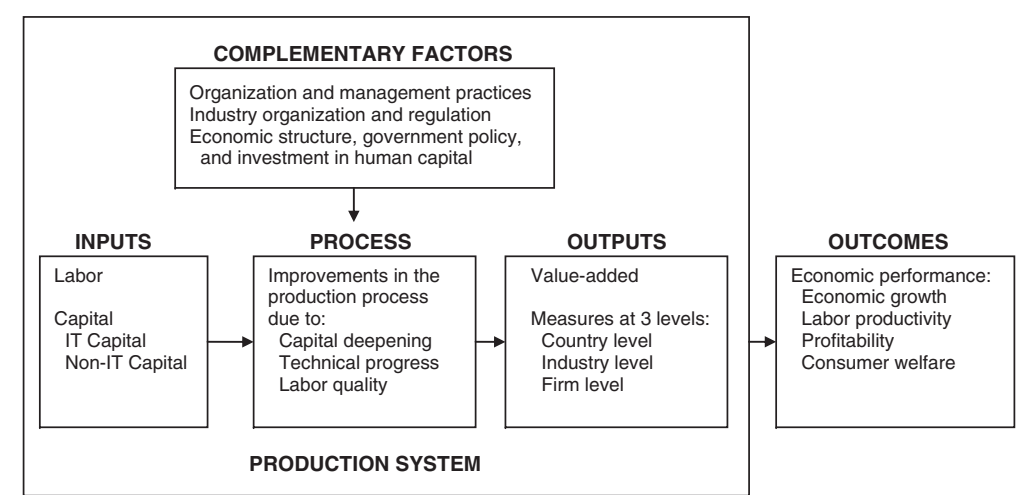

d

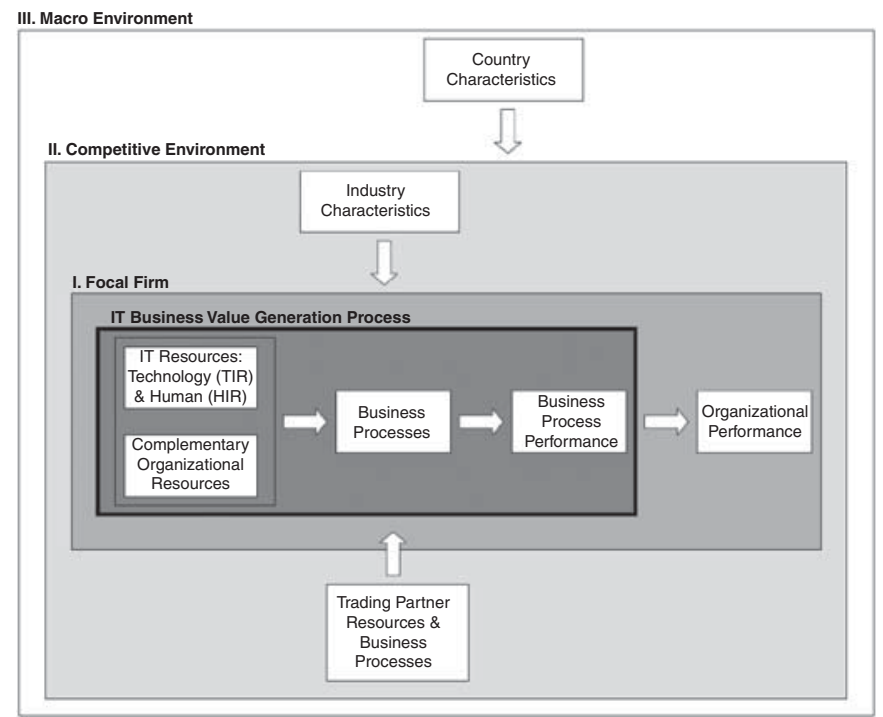

Figure 1 IS business value models in the IS literature. (a) Model of Dehning and Richardson (2002, p.10). Reproduced with permission of and (C) American Accounting Association; (b) Production-oriented model (Dedrick et al, 2003, p.3) C) 2003 Association for Computing Machinery, Inc., Reprinted by permission, http://dx.doi.org/10.1145/ 641865.641866; (c) Process-oriented model (Soh and Markus, 1995, p.37). Reproduced with permission of the authors; (d) Resource-based model (Melville et al, 2004, p.293). Copyright (C) 2004, Regents of the University of Minnesota. Used with permission. 


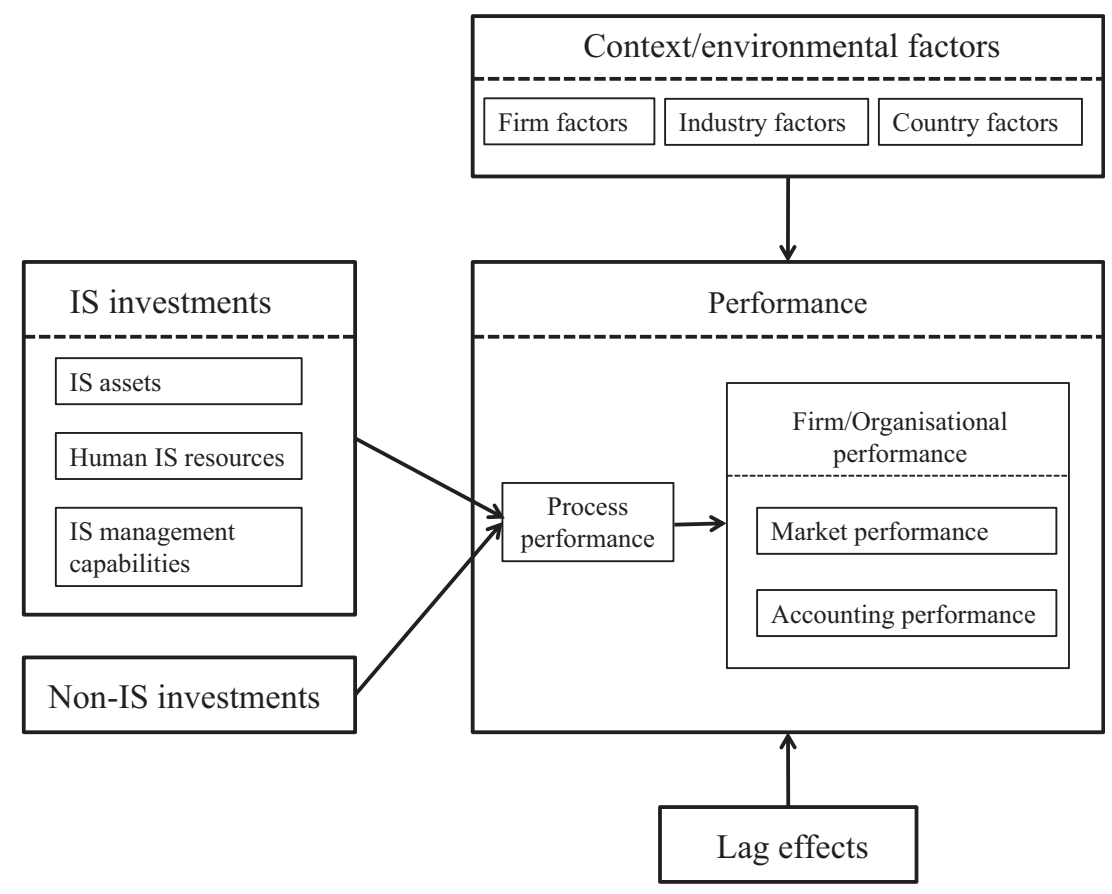

Figure 2 Synthesised IS business value model.

\section{Impact on productivity}

Productivity is probably the most intensively discussed process performance measure in the context of IS investment. Some early studies in the late 1980s and early 1990s (see Brynjolfsson \& Yang (1996) for a comprehensive review) did not find that IS considerably contributed to productivity and economic growth at economy level (Baily, 1986; Roach, 1987; Jorgenson \& Stiroh, 1995), at industry level (Roach, 1991; Berndt \& Morrison, 1995) or at firm level (Loveman, 1994). One impact of these studies was the creation of the term 'productivity paradox'. However, in his comprehensive review of productivity results, Brynjolfsson (1993) concludes that the alleged productivity paradox is due mostly to deficiencies in measurement and methodology (see also Rowe (1994)), and more precisely to mismeasurement of inputs and outputs, lags due to learning and adjustment (see also $\mathrm{Oz}$ (2005)), redistribution and dissipation of profits, and mismanagement of information and technology.

More recent literature draws a more positive picture of the impact on productivity. Although a few studies (Ko \& Bryson, 2002; Ko \& Osei-Bryson, 2004; Lin \& Shao, $2006 \mathrm{~b})$ do not find any evidence of a positive correlation, the opposite results are reported by Aral et al (2007), Brynjolfsson \& Hitt (1996), Brynjolfsson \& Hitt (2000), Kelley (1994), Lin \& Shao (2006a), Neirotti \& Paolucci (2007), Menon et al (2000), Shin (1997), Stiroh (2002), and Swierczek \& Shrestha (2003). In their literature reviews, Devaraj \& Kohli (2000) and Dedrick et al (2003) find an overall positive effect on productivity reported in the literature. However, they also admit that the impact varies widely among different companies. This might explain why some researchers do not find positive correlations between IS investments and productivity in their samples. According to Wan et al (2007) and Dedrick et al (2003), the productivity paradox has been resolved at firm level due to more sophisticated and refined data sources, a shift in the level of analysis towards the firm level, and a refocus on the management of IS. They argue that research has probably better accounted for the four problems cited by Brynjolfsson (1993).

With IS becoming a larger share of total capital investment (Dedrick et al, 2003), more recent studies also find a major impact of IS investments on national productivity and economic growth (Jorgenson \& Stiroh, 2000; Oliner \& Sichel, 2000; Jorgensen, 2001; Dedrick et al, 2003; Lee et al, 2011). In their review, Dedrick et al (2003) conclude that the literature has shown a positive relationship between IS investments, growth and national productivity, at least in developed countries. We found only one empirical study that negates the relationship between IS value and productivity in developed countries (Lin \& Chiang, 2011).

At the industry level, the results are less clear. Devaraj \& Kohli (2000) find mixed results in the literature, and Dedrick et al (2003) identify some positive returns in the form of labour productivity. Han et al (2011) study interindustry IS spillover wherein IS investments made by supplier industries increase the productivity of downstream industries. They find that both IT intensity and competitiveness of the downstream industry moderate the effect of IS spillovers. 


\begin{tabular}{|c|c|}
\hline Area & Key literature findings \\
\hline Performance measures & $\begin{array}{l}\text { Many empirically investigated economic measures, including } \\
\text { productivity, capacity utilisation, product quality, consumer welfare, } \\
\text { various profit ratios and market-oriented measures. } \\
\text { Widely adopted classifications are (1) the model of DeLone and } \\
\text { McLean and (2) the classification that distinguishes between process } \\
\text { performance and firm performance. } \\
\text { The impact of IS investments on firm performance is intermediated } \\
\text { by process performance. }\end{array}$ \\
\hline
\end{tabular}

Impact on productivity Early studies did not find a positive correlation between IS and productivity at firm level, industry level or economy level. More recent studies draw a more positive picture of the impact on productivity: productivity paradox has been resolved at firm level; major impact of IS investments on national productivity and economic growth.

Impact on market performance

No positive correlation between IS investments and Total Shareholder Return (TSR).

Impact of IS investments on stock market reactions is largely determined by the particular type of IS.

Positive correlation between IS investments and Tobin's q.

Impact on accounting performance

IS investments positively affect (1) Return on sales and (2) Operating income to employees.

Positive impact on (1) Return on assets, (2) Return on investment and (3) Return on equity seems to depend largely on lag effects, contextual factors and the level of IS investments compared to total assets.

Contextual factors

Contextual factors can be divided into firm, industry and economic factors.

Alignment of IS with a firm's core competencies and business planning and close ties between IS investments and upper management are crucial for enhanced firm performance.

(1) Industry factors and (2) macro-economic factors are addressed only rarely.

Lag effects
Literature

Brynjolfsson \& Hitt, 1996, Brynjolfsson \& Hitt, 2000, Barua et al, 1995, Thatcher \& Oliver, 2001, Thatcher \& Pingry, 2004a, Thatcher \& Pingry, 2004b, Thatcher \& Pingry, 2007, Barua et al, 1995, Bharadwaj et al, 1999, Lin, 2009, Chen \& Lin, 2009 (1) DeLone \& Mclean, 1992, Seddon, 1997, DeLone \& McLean, 2003, (2) Barua et al, 1995, Dehning \& Richardson, 2002, Melville et al, 2004

Barua et al, 1995, Dehning \& Richardson, 2002, Kim et al, 2006, Lee et al, 2004, Mooney et al, 1995, Shin, 1997, Soh \& Markus, 1995

Brynjolfsson \& Yang, 1996, Baily, 1986 Jorgenson \& Stiroh, 1995, Roach, 1987, Berndt \& Morrison, 1995, Roach, 1991, Loveman, 1994

Aral et al, 2007, Brynjolfsson \& Hitt, 1996, Brynjolfsson \& Hitt, 2000, Kelley, 1994, Lin \& Shao, 2006a, Neirotti \& Paolucci, 2007, Menon et al, 2000, Shin, 1997, Stiroh, 2002, Swierczek \& Shrestha, 2003, Devaraj \& Kohli, 2000, Dedrick et al, 2003, Jorgensen, 2001, Jorgenson \& Stiroh, 2000, Oliner \& Sichel, 2000, Lee et al, 2011

Tam, 1998, Brynjolfsson \& Hitt, 1996

Dos Santos et al, 1993, Im et al, 2001, Richardson \& Zmud, 2002, Dehning et al, 2003 Bharadwaj et al, 1999, Brynjolfsson \& Yang, 1999, Brynjolfsson et al, 2002

(1) Bharadwaj, 2000, Dehning \& Stratopoulos, 2002, Kim et al, 2009, Santhanam \& Hartono, 2003, Zhang, 2005; (2) Bharadwaj, 2000, Santhanam \& Hartono, 2003

(1) Bharadwaj, 2000, Dehning \& Stratopoulos, 2002, Hitt \& Brynjolfsson, 1996, Kim et al, 2009, Peslak, 2003, Rai et al, 1997, Santhanam \& Hartono, 2003, Stratopoulos \& Dehning, 2000, Tam, 1998; (2) Hayes et al, 2001, Mahmood \& Mann, 2005, Peslak, 2003, Stratopoulos \& Dehning, 2000; (3) Alpar \& Kim, 1990, Beccalli, 2007, Peslak, 2003, Rai et al, 1997, Shin, 2006, Stratopoulos \& Dehning, 2000, Tam, 1998

Barua et al, 1996, Bharadwaj, 2000, Davern \& Kauffman, 2000, Dehning \& Richardson, 2002, Ko \& Osei-Bryson, 2004, Melville et al, 2004, Zhu et al, 2004 Chari et al, 2008, Dos Santos et al, 1996, Floyd \& Wooldridge, 1990, Li \& Ye, 1999, Ravichandran \& Lertwongsatien, 2005

(1) Lin \& Shao, 2006a, Sircar et al, 2000, Lim et al, 2004, Melville et al, 2007, (2) Kim et al, 2009, Swierczek \& Shrestha, 2003, Zhu et al, 2004

Kauffman \& Weill, 1989, Stiroh, 2002, Weill \& Olson, 1989, Brynjolfsson \& Hitt, 1998, Jain, 2005, Mahmood \& Mann, 2005, Oz, 2005, Santhanam \& Hartono, 2003, Das et al, 2011
Mismeasurement of IS investment impact may be rooted in the ignorance of effects delayed by years. 
To sum up, the recent literature paints a positive picture of IS-based productivity gains overall, at least at firm level and national level. However, correlations between IS investments and productivity vary widely among companies, and IS-based productivity gains at the national level are limited to developed countries.

\section{Impact on market performance}

Researchers have shown some interest in analysing the extent to which IS investments are correlated with increased (stock) market performance of firms. Tam (1998), Dedrick et al (2003) and Brynjolfsson \& Hitt (1996) investigate the impact on 'Total Shareholder Return' and find no correlation and a negative correlation, respectively. Dos Santos et al (1993), Im et al (2001), Richardson \& Zmud (2002) and Dehning et al (2003) analyse stock market reactions and find that the impact is largely determined by the particular type of IS and its strategic role. In more recent studies, Bharadwaj et al (2009) report that the market responds (in terms of stock prices) more negatively to implementation failures affecting new systems than to operating failures involving current systems, and Dehning et al (2007a) find that IS spending increases earnings forecast dispersion and error, which in turn might affect the market value of the firm. Bharadwaj et al (1999), Brynjolfsson \& Yang (1999), Brynjolfsson et al (2002) and Peslak (2003) focus on Tobin's $\mathrm{q}$ and find positive correlations. Kim \& Mithas (2011) investigate the business value of IS in terms of performance in bond markets, and they find a significant association between a firm's IS intensity and bond ratings at issuance. In their literature review, Dehning \& Richardson (2002) conclude that market values increase by five to 20 times the amount spent on IS, and that shareholders value strategic IS investments. Brynjolfsson \& Yang (1999) and Brynjolfsson et al (2000) suggest that adjustment costs and intangible assets, such as software, training and organisational transformations, may provide an explanation for the high market valuation found for IS.

\section{Impact on accounting performance}

The impact of IS investments on accounting performance is one the most intensively studied research areas in IS business value research, at least with regard to profit ratios. While only very few studies analyse cost ratios (Bharadwaj, 2000; Santhanam \& Hartono, 2003) or turnover ratios (Barua et al, 1995; Dehning \& Stratopoulos, 2002), many studies address profit ratios: IS investments seem to positively affect 'Return on Sales' (Tam, 1998; Bharadwaj, 2000; Dehning \& Stratopoulos, 2002; Santhanam \& Hartono, 2003; Zhang, 2005; Kim et al, 2009) and 'operating income to employees' (Bharadwaj, 2000; Santhanam \& Hartono, 2003), while the positive impact on 'Return on Assets' (Hitt \& Brynjolfsson, 1996; Rai et al, 1997; Tam, 1998; Bharadwaj, 2000; Stratopoulos \& Dehning, 2000; Dehning \& Stratopoulos, 2002; Peslak, 2003; Santhanam \& Hartono, 2003; Kim et al, 2009),
'Return on Investment' (Stratopoulos \& Dehning, 2000; Hayes et al, 2001; Peslak, 2003; Mahmood \& Mann, 2005) and Return on Equity (ROE) (Alpar \& Kim, 1990; Rai et al, 1997; Tam, 1998; Stratopoulos \& Dehning, 2000; Peslak, 2003; Shin, 2006; Beccalli, 2007; Dehning et al, 2008) is less clear, and seems to depend largely on lag effects, contextual factors and the level of IS investments compared to total assets.

\section{Contextual factors}

The important role of contextual factors with regard to the impact of IS investments has been identified in several works (Barua et al, 1995; Milgrom \& Roberts, 1995; Davern \& Kauffman, 2000; Richardson \& Zmud, 2002; Ko \& OseiBryson, 2004). As Richardson \& Zmud (2002, p. 1) point out, The salient question, then, is not 'Does IT pay off?' but rather 'Under what conditions does IT pay off?' There is a broad consensus in the literature that contextual factors should be divided into firm, industry and macro-economic factors (Weill, 1992; Barua et al, 1996; Bharadwaj, 2000; Davern \& Kauffman, 2000; Dehning \& Richardson, 2002; Ko \& Osei-Bryson, 2004; Melville et al, 2004; Zhu et al, 2004). For example, firm factors comprise employees' bias towards or against the adoption of new technologies or corporate strategy (Harris \& Katz, 1991; Venkatraman, 1994), operational capabilities (Lee et al, 2007), organisational practices (Lee et al, 2007; Poon et al, 2009), firm boundary strategy (Dewan \& Ren, 2011) and managerial skills (Dong et al, 2009), while industry factors comprise technological standards and the intensity of competition, and macro-economic factors include laws and a country's technological infrastructure.

Most of the studies that address contextual factors focus on firm factors (Floyd \& Wooldridge, 1990; Dos Santos et al, 1996; Armstrong \& Sambamurthy, 1999; Li \& Ye, 1999; Ravichandran \& Lertwongsatien, 2005; Chari et al, 2008). These studies strongly suggest that both the alignment of IS with a firm's core competencies and business planning, close ties between IS investments and upper management, and CIOs' business and IS knowledge are crucial for IS-driven enhanced firm performance. Other firm factors have proven to have either low explanatory power or none at all, or require more comprehensive investigation. Industry factors have been addressed by Lin \& Shao (2006a), Sircar et al (2000), Lim et al (2004), and Melville et al (2007), and macroeconomic factors have been analysed by Kim et al (2009), Swierczek \& Shrestha (2003) and Zhu et al (2004). However, the body of literature that addresses industry or macro-economic factors is still too small to draw a clear picture.

\section{Lag effects}

It is argued in the literature that a mismeasurement of IS investment impact may be rooted in inappropriate methodology when delayed effects need to be considered, but are ignored (Kauffman \& Weill, 1989; Weill \& Olson, 1989; Stiroh, 2002; Oz, 2005). Brynjolfsson (1993) 
and Brynjolfsson \& Yang (1996) even find in their reviews that lags due to learning and adjustment have not been sufficiently considered in productivity studies, and that this shortcoming in methodology is one of four explanations for the 'IT productivity paradox'. Some empirical studies (Brynjolfsson \& Hitt, 1998; Santhanam \& Hartono, 2003; Jain, 2005; Mahmood \& Mann, 2005; Das et al, 2011) account for this criticism, and find that lags may exist and that several years may pass before an organisation's investment in IS bears fruit.

\section{Summary of literature findings}

The key findings of IS business value literature are summarized in Table 1.

\section{Identifying research gaps}

Despite the large body of literature on IS business value, including many empirical studies on the economic impact of IS investments, dissenting opinions on IS value (West \& Courtney, 1993; Hitt \& Brynjolfsson, 1996; Carr, 2003) show that IS researchers have not fully managed to identify and explain the economic relevance of IS. In fact, our study of the literature reveals inconclusive and conflicting results in many areas, including correlations between IS investments and productivity, market performance, and accounting performance. Overall, after many years of research, the contribution and importance of IS regarding the creation of various forms of business value still seem to remain a 'grey box'.

We hypothesise that the existence of the grey box is largely rooted in the fact that past research on IS business value has underemphasised increasingly important research areas and questions - more specifically (1) how to get a consistent and comprehensive understanding of the complex 'IS business value construct', (2) how to disaggregate overall IS investments in order to distinguish IS assets that create value from those which do not, and (3) how, why and when IS assets create capabilities with which they jointly create and preserve business value. We look at these questions in more detail in the following subsections.

\section{Ambiguity and fuzziness of the 'IS business value' construct}

A substantial part of IS value manifests in various nonfinancial, intangible value items. Of particular importance are internal capabilities, the neglect of which leads to the underestimation of the overall economic benefit of IS investments (Davern \& Wilkin, 2010). We refer to this deficiency as ambiguity and fuzziness of the IS business construct, and we unfold the issue in this subsection.

The research on IS business value is multifaceted, as the previous section reveals. The drivers of specific research directions and their related performance indicators are probably due to the various home disciplines of researchers to a great extent, and to theories and methodologies adopted from other economic fields (for a more detailed analysis, see the subsection 'Theoretical paradigms used in IS business value research'). The diversity of efforts in considering different impacts of IS investments should be acknowledged as a necessary approach in order to cover IS business value comprehensively. It accounts for the observation of Kohli \& Grover (2008, p. 26) that IS-based value manifests itself in many ways.

However, having analysed a substantial body of literature on IS business value, it seems that the discussion frays into many lines of thought in various directions by contemporaneously losing track of the 'IS value construct'. For example, only a few studies (Hitt \& Brynjolfsson, 1996; Thatcher \& Pingry, 2004a; Kohli \& Grover, 2008) recognise the importance of linkages between different types of performance.

What makes it extremely challenging to capture IS business value comprehensively is the fact that it also manifests in ways that are hard to measure with quantitative indicators. For example, Avgerou (2001) argues that the value of (interorganisational) IS should also be seen with regard to its contribution to securing a firm's competitive position by protecting resources. The importance of product and service innovations induced through IS is also highlighted in the literature (Aral \& Weill, 2007; Zammuto et al, 2007). While resource protection and product and service provision are market-oriented capabilities that are assumed to have a direct impact on the strategic position of a firm, internal capabilities (sometimes referred to as 'intangibles') created through IS are deemed important parts of IS business value as well (Shin, 1997; Bannister \& Remenyi, 2000; Brynjolfsson \& Hitt, 2000; Devaraj \& Kohli, 2000; Irani \& Love, 2001; Irani, 2002; Oz, 2005). For example, implications of IS use at the individual level, and capabilities and knowledge at the organisational level (Kohli \& Grover, 2008), such as redesigned business processes, better decision-making and improved coordination flexibility (Soh \& Markus, 1995), may have either an intermediate, a delayed or a hidden impact on performance that is measured by traditional economic indicators. However, only few researchers have empirically addressed internal capabilities in their empirical studies. For example, Ayal \& Seidmann (2009) analyse health (in the context of a case study in medical imaging informatics), Barua et al (1995) investigate relative inferior quality, and Bresnahan et al (2002) focus on product and service innovations, and specific types of work organisation. Apparently, it has either not been widely acknowledged or has at least been underestimated in the IS business value community that internal capabilities must not be overseen when IS business value is addressed. Consequently, we argue that a systemisation of internal capabilities should be included when we theorise on the IS business value construct.

In the presence of many empirical studies on the impact of IS investments on economic performance, the perspective of the ultimate meaning of performance (gains or losses) has been suggested. Alshawi et al (2003) widen the view on IS business value: An outcome is the result of introducing a new IT system, a benefit is what is 
subsequently derived if the new capability is exploited. For example, a system may have as an outcome that a task can now be performed more quickly. However, [...] the benefit often comes from what is done with the saved time, for example ensuring the product reaches the customer more quickly. Furthermore, the assessment of outcomes may also depend on what competitors have achieved (Dehning \& Richardson, 2002). While these arguments call for a context-specific definition and assessment of business value, Sylla \& Wen (2002, p. 242) note that the value may depend upon the subjective preferences of those who perform the evaluation. For example, a decrease in personnel costs is usually positively assessed by managers, while staff councils may regard this decrease negatively. This argument indicates the necessity to distinguish between performance, which is measured by means of economic indicators, and its (potentially different) values in terms of the subjective interpretation of (different) stakeholders. While the former perspective is referred to as 'outcome approach' (Sethi \& King, 1994), the latter corresponds to what is referred to as 'perceived benefit' (Tallon et al, 2000; Chau et al, 2007). However, the literature is remarkably silent on the aforementioned aspects of IS business value.

To sum up deficiencies in the research on the ambiguity and fuzziness of the 'IS business value' construct, we argue that our future efforts to develop a consistent and comprehensive understanding of the complex 'IS business value construct' should account for (a) linkages between different types of performance, (b) market-oriented capabilities that go beyond hard indicators, (c) various types of internal capabilities, (d) an environmentally oriented understanding, and (e) perceived benefits that are dependent on the respective stakeholders.

\section{Neglected disaggregation of IS investments}

While the ambiguity and fuzziness of the IS business value construct, discussed in the preceding subsection is an 'output problem', we also face an 'input problem', manifested in the usage and questionable comparison of different types of IS expenditures (Oz, 2005). Consequently, it has been widely argued in the literature that better insights into the way IS investments induce superior business performance require a breakdown of IS investments into single IS assets (Weill, 1992; Mahmood \& Mann, 1993; Ross et al, 1996; Rai et al, 1997; Bharadwaj, 2000; Sircar et al, 2000; Orlikowski \& Iacono, 2001; Melville et al, 2004). We follow this path in this subsection.

The analysis of literature findings in the previous section reveals subfields of IS business value research, where the impact of IS investments on various economic performance indicators is not clear due to contradictory empirical results. Taking a closer look at this body of literature, it becomes obvious that most empirical studies on IS business value consider IS to be an aggregate, uniform asset (Bharadwaj et al, 1999) or divide IS investments into capital and labour stock (Brynjolfsson
\& Hitt, 1996; Hitt \& Brynjolfsson, 1996; Bharadwaj, 2000); we found only 22 empirical studies (see below in this subsection) that analyse the economic impact of specific types of IS assets. However, it seems questionable whether this high-level perspective is appropriate for identifying and explaining IS-induced value. For example, investments of equal amounts in the substitution of outdated PCs for employees and in a customer relationship management (CRM) system, which enables the firm to identify customer behaviour at the individual level and to derive personalised customer needs, are likely to have different impacts on the competitive position of the firm. Furthermore, our literature review reveals that the impact of IS investments on (stock) market reactions is largely determined by the particular type of IS. Orlikowski \& Iacono (2001) find that many articles fail to be specific about the 'IT artefact', Melville et al (2004) note that the IS community still has divergent perspectives on the IT construct, which depend on the specific context of research, and Aral \& Weill (2007) conclude that [...]the majority of firm-level analysis measures IT in the aggregate. As a result, we know little about the relative performance contributions of different types of IT investments and whether different IT investments impact different aspects of firm performance.

Following this research path, several authors began to analyse the impact of specific IS assets on selected firm performance criteria. However, the resulting picture is quite mixed: Several studies (Hitt \& Brynjolfsson, 1994; Barua et al, 1995; Rai et al, 1997; Tam, 1998; Sircar et al, 2000; Mahmood \& Mann, 2005; Martin-Oliver \& Salas-Fumas, 2008; Thouin et al, 2008) analyse the impact of IT capital, and find no correlation with stock market behaviour, mixed results regarding profitability ratios, and a positive correlation with profitability in terms of 'sales' and 'value added'. However, the studies do not investigate whether the impact depends on contextual factors. In addition, most studies refer to old data (1980s and 1990s). Some studies are even more specialised, and analyse the impact of hardware expenditures or expenditures based on investments in software (Rai et al, 1997; Beccalli, 2007), production-oriented software (Barua et al, 1995), ERP systems (Poston \& Grabski, 2000; Hayes et al, 2001; McAfee, 2002; Karimi et al, 2007; Staehr, 2010), e-commerce systems (Subramani \& Walden, 2001; Zhu \& Kraemer, 2005; Ordanini \& Rubera, 2010; Tan et al, 2010), supply chain systems (Kim et al, 2006; Dehning et al, 2007b; Vickery et al, 2010), infrastructure (Rai et al, 1997; Byrd \& Turner, 2000; Chatterjee et al, 2002; Aral et al, 2007) and Web 2.0 technologies (Andriole, 2010). Studies that are related to IS personnel and training expenditures are provided by Chatterjee et al (2001), Mahmood \& Mann (2005), Sircar et al (2000) and Thouin et al (2008).

On the basis of the few and mixed results concerning the impact of investments in various IS assets [...] it appears that firms benefit unequally from their different IT investments (Bharadwaj et al, 1999, p. 1020). Mutch (2010) argues that one explanation for this phenomenon is 
the effects of combinations of particular IS assets. This argument is convincing when we acknowledge, for example, that purchasing an email system is rather useless unless employees are trained to use the system effectively. However, the literature has been remarkably silent on synergies and complementarities of IS assets (Cho \& Shaw, 2009). Orlikowski \& Iacono (2001) argue that there are compelling theoretical arguments from works on technological change in organisations to be more specific about the form IS investments take.

To sum up deficiencies in research on the disaggregation of IS assets, we argue that gaining further insights into how and why IS creates business value requires (a) the conceptual and empirical disaggregation of IS assets, (b) the accounting for the strategic and resourceoriented relevance in the process of disaggregation, and (c) the analysis of synergies and complementarities of IS assets.

\section{IS business value creation process as grey box}

The literature provides some streams of research on how, why and when IS creates business value. For example, results indicate that IS assets and complementary capabilities affect each other and can even co-create competitive value. However, the particular relationships between IS assets and complementary capabilities, their roles in the value generation process, and the conditions under which competitive value is created remain unclear. We hypothesise that this epistemological issue is one of the main reasons why the IS community still lacks a theory of IS business value (among the many theories listed on the AIS website (Schneberger \& Wade, 2010), no theory of IS business value is provided). Our argument is based on the understanding that a theory is required to have an explanatory component included (Dubin, 1978; Whetten, 1989; Sutton \& Staw, 1995). Due to the apparent importance of opening the grey box of IS business value creation, we discuss this issue in more detail in the following paragraphs.

Our analysis of the literature shows that the vast majority of both theoretical and empirical research papers on IS business value are concerned with quantifying the impact of IS investments on various forms of performance, such as ROA, labour productivity, inventory turnover and Tobin's q. This perspective is outputoriented, allows the identification of correlations between IS inputs and economic performance, and is capable of answering the question of what IS has induced. Since the results of this research stream are partially conflicting, as Table 1 shows (see the previous section), researchers are interested in exploring the reasons for the divergent results. However, the output-oriented perspective does not provide explanations for the divergence in economic performance, as it does not allow an analysis of how, why and when IS investments create business value. As Sircar et al (1998) note, the analysis of the impact of IS on selected outputs suffers the problem that firm performance is also simultaneously affected by a host of other external and internal factors, making it exceedingly difficult to isolate the influence of IT alone and to develop causal relationships.

Researchers have started addressing the 'how' and 'why' questions in multiple ways. One stream of research conceptualises and investigates (the mediating role of) internal capabilities (Shin, 1997; Bannister \& Remenyi, 2000; Brynjolfsson \& Hitt, 2000; Devaraj \& Kohli, 2000; Irani \& Love, 2001; Irani, 2002; Oz, 2005). A second stream acknowledges the importance of complementarities, and, in particular, IS capabilities (Aral \& Weill, 2007; Hsieh et al, 2011; Kim et al, 2011; Mithas et al, 2011) and socio-organisational capabilities (DeSanctis \& Poole, 1994; Rowe, 1994; Orlikowski, 1996; Whittington et al, 1999; Avgerou, 2001; Pinsonneault \& Kraemer, 2002; Aral \& Weill, 2007; Kane \& Alavi, 2007; Leonardi, 2007; Zammuto et al, 2007; Mutch, 2010; Tambe et al, 2012). It acknowledges the existence of time-variant relationships between complementarities and IS. This perspective is mirrored in the conceptualization of IS innovation processes and socio-organizational changes (Gregor et al, 2006). However, the discussion of the complementarities of IS assets, IS capabilities and socioorganisational capabilities is fragmented and produces conflicting results. For example, the existence of interdependencies between IS innovation and socioorganisational capabilities is stressed in many of the abovementioned works, which suggest a symbiotic relationship (Zammuto et al, 2007), while others, such as Avgerou (2000), adopt an institutionalisation perspective and argue that IS innovation relies on its own institutional forces. The relationship between IS capabilities and socio-organisational capabilities has also been rarely addressed (see, for example, Rai \& Tang, 2010).

Acknowledging the importance of considering relationships between IS assets and firms' capabilities, the question arises of how the complementarities co-create business value in terms of various competitive goals, such as the protection of resources (Avgerou, 2001), innovations and market performance. We see some fragmented discussion of this important issue in the literature. For example, Dedrick et al (2003) find that IS is an enabler of organisational changes that can lead to additional productivity gains, which can in turn lead to lower product prices and an increased market share. Aral \& Weill (2007) argue that investments in specific IS assets explain performance differences only along dimensions consistent with their strategic purpose. Bhatt \& Grover (2005) suggest that the quality of IS business expertise can form capabilities that have a significant effect on competitive advantage.

Overall, the value creation process remains unclear in terms of how, why and when IS assets and organisational capabilities are transformed into competitive strength. For example, Rowe (1994) argues that competitive value can be created in specific periods only, but the literature does not provide many contributions on this issue. Gaining insights into this subfield is of particular importance 
Table 2 Deficiencies in IS business value research

\begin{tabular}{|c|c|c|}
\hline Research gaps & Deficiencies in research & References \\
\hline $\begin{array}{l}\text { Ambiguity and fuzziness } \\
\text { of the 'IS business value' } \\
\text { construct }\end{array}$ & $\begin{array}{l}\text { - Discussion on IS business value frays into many lines of } \\
\text { thought and loses track of the 'IS value' construct. } \\
\text { - Market-oriented capabilities and internal capabilities are } \\
\text { out of the scope of value consideration. } \\
\text { - Understanding of value lacks the consideration of the } \\
\text { environment. }\end{array}$ & $\begin{array}{l}\text { Alshawi et al (2003), Ayal \& Seidmann, } \\
\text { 2009, Barua et al, 1995, Bhatt \& Grover, } \\
\text { 2005, Bresnahan et al, 2002, Davern \& } \\
\text { Wilkin, 2010, Dedrick et al, 2003, } \\
\text { Dehning \& Richardson, 2002, Kohli \& } \\
\text { Grover, 2008, McAfee, 2002, Oz, 2005, } \\
\text { Soh \& Markus, 1995, Sylla \& Wen, } 2002\end{array}$ \\
\hline $\begin{array}{l}\text { Neglected disaggregation } \\
\text { of IS investments }\end{array}$ & $\begin{array}{l}\text { - Only little is known about the relative performance } \\
\text { contributions of different types of IS investments and } \\
\text { whether different IS investments impact different aspects } \\
\text { of firm performance. } \\
\text { - Empirical results of different studies are hard to compare } \\
\text { (danger of comparing apples with pears). } \\
\text { - Impact of specific IS assets on strategic and resource- } \\
\text { oriented position of firms is hardly understood. } \\
\text { - Synergies and complementarities of IS assets are not } \\
\text { identified. }\end{array}$ & $\begin{array}{l}\text { Aral \& Weill, 2007, Bharadwaj et al, } \\
\text { 1999, Cho \& Shaw, 2009, Mahmood \& } \\
\text { Mann, 1993, Melville et al, 2004, Mutch, } \\
\text { 2010, Orlikowski \& lacono, 2001, Rai } \\
\text { et al, 1997, Sircar et al, 2000, Weill, } 1992\end{array}$ \\
\hline $\begin{array}{l}\text { IS business value creation } \\
\text { process as grey box }\end{array}$ & $\begin{array}{l}\text { - Time-variant relationships between IS assets and } \\
\text { complementary capabilities remain unclear. } \\
\text { - Value generation process still needs to be uncovered. } \\
\text { - Time issues in creating competitive value are not } \\
\text { sufficiently addressed. } \\
\text { - Explanations of unanticipated consequences of IS are still } \\
\text { required. } \\
\text { - No theory on IS business value exists. }\end{array}$ & $\begin{array}{l}\text { Aral \& Weill, 2007, Avison et al, 2006, } \\
\text { Avgerou, 2000, Avgerou, 2001, Bhatt \& } \\
\text { Grover, 2005, Dedrick et al, 2003, } \\
\text { DeSanctis \& Poole, 1994, Kane \& Alavi, } \\
\text { 2007, Leonardi, 2007, Markus \& Robey, } \\
\text { 2004, Mutch, 2010, Nelson, 2007, } \\
\text { Orlikowski, 1996, Pinsonneault \& } \\
\text { Kraemer, 2002, Rai \& Tang, 2010, Rowe, } \\
\text { 1994, Whittington et al, 1999, Zammuto } \\
\text { et al, } 2007\end{array}$ \\
\hline
\end{tabular}

for practitioners and also for scholars engaged in fierce debate about the competitive advantage of IS (Feeny \& Ives, 1990; West \& Courtney, 1993; Hitt \& Brynjolfsson, 1996; Zhang \& Lado, 2001; Carr, 2003; Bhatt \& Grover, 2005; Piccoli \& Ives, 2005).

While the above discussion implicitly assumes that there are many ways in which IS can add value, an unbiased discussion of the economic impact of IS investments requires us to think also about barriers or challenges to IS value generation and unanticipated consequences be they positive or negative - of using IS. For example, reviewing three large Australian IS projects and their failures, Avison et al (2006) find that managerial IS unconsciousness and failure in IS governance, defined as patterns of authority for key IS activities in firms, including IS infrastructure, IS use and project management (Sambamurthy \& Zmud, 2000), can even lead to the bankruptcy of private companies and the waste of millions of dollars of taxpayers' money. The authors also argue that the importance of IS governance is largely ignored in the failure literature (Avison \& Wilson, 2002). In the evaluation of 99 retrospectives of IS projects conducted in 74 organisations, Nelson (2007) finds that poor estimation and/or scheduling process, ineffective stakeholder management and insufficient risk management are the top three mistakes made, and which occurred in approximately half of the projects examined. Interestingly, the findings also suggest that none of the top 10 mistakes was a technology mistake. The author concludes that project managers should be, first and foremost, experts in managing processes and people. A more theoretical approach on unanticipated consequences of IS use is conducted by Markus \& Robey (2004), who examine four classes of explanations of unintended consequences of IS use. They suggest theories that (1) explain patterns of use and patterns of consequences in terms of affordances of IS, (2) explain patterns of use in terms of human agency, (3) emphasise complex interactions between technology use and other aspects of the organisational context of use, and (4) emphasise complex interactions between technology use and social systems, including cultural belief systems and politics. While Markus and Robey draw on 'divergent disciplinary orientations' and thereby suggest a rich set of theoretical underpinnings, research still lacks an integrated theory (and its empirical validation) concerning unanticipated consequences of IS use, as the authors themselves admit. 


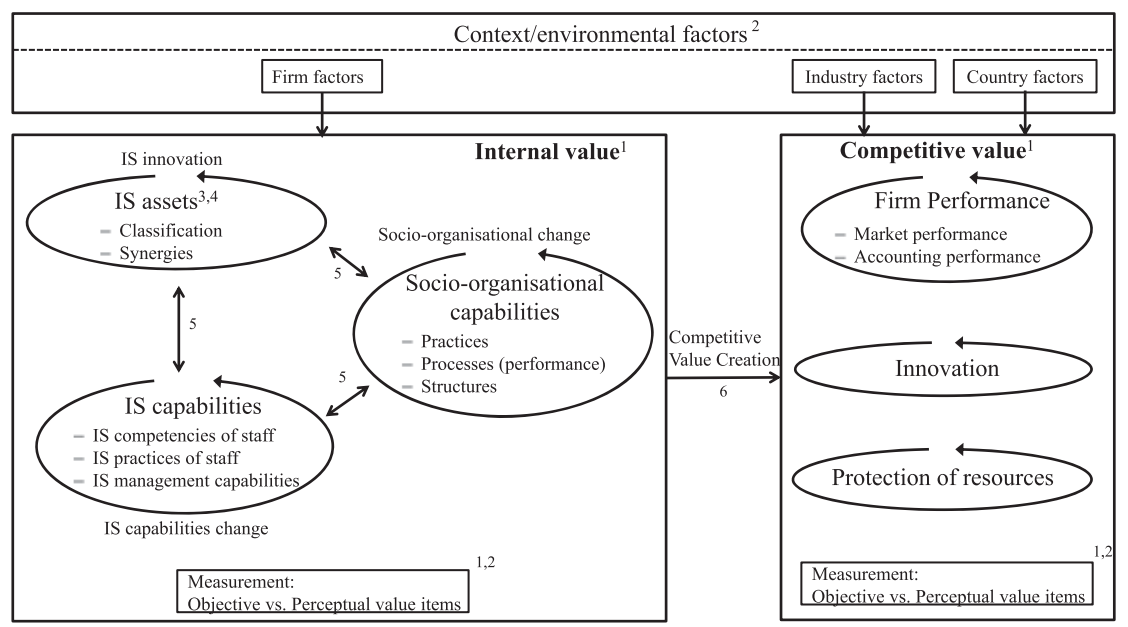

Figure 3 IS business value research agenda.

Note: Numbers indicate the corresponding research thrust.

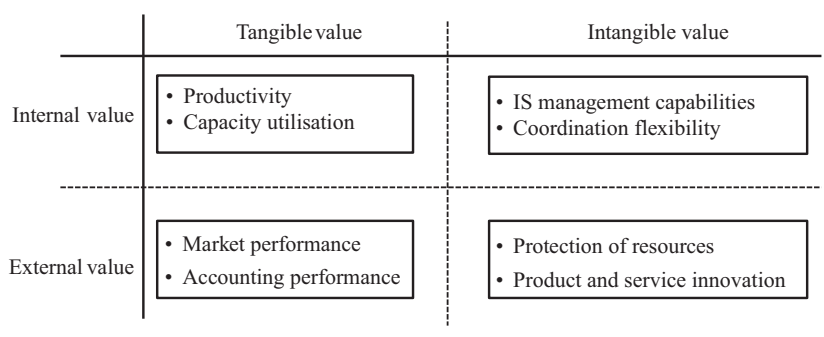

Figure 4 Taxonomy of IS business value types and examples.

\section{Summary of identified deficiencies in research}

The identified deficiencies in IS business value research are summarised in Table 2, grouped by aggregated research gaps and supported with references.

\section{Research agenda}

In this section we suggest a research agenda that links existing IS business value knowledge - condensed into the synthesised IS business value model shown in Figure 2 with the identified deficiencies in IS business value research, considers interdependencies between the deficiencies, and suggests research paths for overcoming them. Our research agenda is based on prior work (Schryen, 2011) shifts the focus towards the diversity of (internal and competitive) IS business value constructs, the causal nature of their relationships, and the resulting processes of value creation. In particular, it extends the view of IS business value with IS innovation, change in IS capabilities and socio-organisational change as new focal constructs of internal value, and with innovation and protection of resources as additional constructs of competitive value. Figure 3 shows a graphical representation of the research agenda, which is broken down into research thrusts and related research paths.

\section{Ambiguity and fuzziness of the 'IS business value' construct}

The identification of research deficiencies reveals that the object of investigation, the 'IS business value construct', has been defined neither precisely nor comprehensively, which has resulted in an ambiguity and fuzziness of IS business value. Accounting for our observation that the discussion frays into too many lines of thought by contemporaneously losing track of the 'IS business value construct', we define

Research thrust 1: How can we yield a comprehensive, consistent and precise understanding of the multifaceted construct 'IS business value'?

To study this question, we need to conceptualise, disaggregate and operationalise the multifaceted construct 'IS business value'. Regarding the conceptualisation, we argue that researchers have implicitly adopted (and sometimes even confused) two dimensions of IS business value. The first dimension distinguishes internal $v s$ competitive value. Internal value is achieved when IS contributes to redesigned business processes, better decision-making, improved coordination flexibility (Soh \& Markus, 1995; Kohli \& Grover, 2008; Ramirez et al, 2010) and productivity (Brynjolfsson \& Hitt, 1996, 2000). Examining both the IS literature and the organisation literature, we argue that IS innovation, change in IS capabilities and socio-organisational change (Gregor et al, 2006; Aral \& Weill, 2007) are key focal constructs of internal IS business value; we discuss these constructs in detail in the context of internal value creation (see research thrust 5). In contrast, competitive value is achieved when IS supports market-oriented performance, such as stock market performance reactions (Dos Santos et al, 1993; Im et al, 2001) and profit ratios (Bharadwaj, 2000; Santhanam \& Hartono, 2003), and innovation and 
protection of resources (Avgerou, 2001). Internal value is assumed to have a direct impact on competitive value; we discuss this issue in detail in the context of competitive value creation (see research thrust 6). The second dimension distinguishes tangible value, operationalised through performance measures, and intangible value, such as organisational capabilities (Kohli \& Grover, 2008) or the strategic position of a firm (Irani, 2002). These examples show that intangible value can manifest in both internal and competitive value. Thus, we argue that the two dimensions are orthogonal (see Figure 4) and form an appropriate taxonomy of types of IS business value. As a consequence, 'internal value' and 'intangible value' should not be used synonymously, as is sometimes done in the literature.

We suggest that the provided taxonomy be used as a starting point to further disaggregate and operationalise the four types of IS business value. Key tasks in this regard are (a) the instantiation of the taxonomy in terms of extending the lists of examples with further value types (e.g. customer satisfaction), (b) the identification of value items with which the respective value can be measured (e.g. customers' attitude towards the company and the offered product), and (c) identification and development of methodologies that allow measurement (e.g. interviews). While task (a) is supported by the comprehensive body of IS business value literature (see, for example, Soh \& Markus, 1995; Shin, 1997; Bannister \& Remenyi, 2000; Brynjolfsson \& Hitt, 2000; Devaraj \& Kohli, 2000; Irani \& Love, 2001; Irani, 2002; Oz, 2005), task (b) seems to be more challenging, particularly for intangible value items. We suggest two (orthogonal) approaches for measuring intangible value items: (i) We argue that the scale level of a value item does not necessarily need to be 'cardinal' when it is difficult or even impossible to find reliable numerical data. In this case it might be legitimate to compare the current state with former states or with states of competitors and to derive a ranking. For example, the measurement of the value item 'customer satisfaction' can lead to the results 'customer satisfaction improved compared to previous year' or 'customer satisfaction was better than that of competitors'. (ii) A second approach for measuring intangible value items is the use of perceptual measures (Seddon, 1997; Chau et al, 2007) when objective measures are impossible or difficult to perform. For example, user satisfaction as a value at the individual level and the strategic position of a firm as a value at the organisational level are value items that are appropriate candidates for perceptual measures. In contrast to objective measures, perceptual measures are inherently linked to subjective attitudes of the respective evaluators; we discuss this issue in detail when describing the 'context of evaluation' (see research thrust 2). Regarding task (c), an excellent starting point is the work of Bannister \& Remenyi (2000), who categorise an abundance of methodologies related to respective value items.
As the discussion of measuring intangible value items revealed, the use of ordinal scale level and perceptual measures is tied to the competitive environment and the individuals who perform the evaluation. Both aspects can be subsumed under the concept 'context of evaluation'. However, we argue that the consideration of this context of evaluation is not only necessary with regard to intangible value items but also with regard to tangible items. For example, the meaningful evaluation of stock market reactions may also depend on what competitors have achieved on the stock market (Dehning \& Richardson, 2002) and how general stock market conditions have developed. It should be noted that these environmental conditions ought to be considered, although stock market reactions can be evaluated both quantitatively and objectively. However, our literature review revealed that IS business value research widely ignores the consideration of the context in which business value is assessed. Thus we define

Research thrust 2: How can the assessment of (internal and competitive) business value account for the context of evaluation, and in particular the firm, industry and country environment and the preferences of evaluators?

While research thrust 1 indicates that measuring the extent to which (internal and competitive) value has been created is a key question for future research, a related but different question is how the measured extent can be assessed when accounting for environmental factors. The significant role of environmental factors, divided into firm, industry and country factors (Barua et al, 1996; Dehning \& Richardson, 2002; Melville et al, 2004) is widely identified in the literature. However, while their explanatory power for IS business value is recognised with regard to firm factors (Floyd \& Wooldridge, 1990; Dos Santos et al, 1996; Li \& Ye, 1999; Ravichandran \& Lertwongsatien, 2005; Chari et al, 2008) and to industry and country factors (Sircar et al, 2000; Swierczek \& Shrestha, 2003; Lim et al, 2004; Melville et al, 2004; Lin \& Shao, 2006a; Kim et al, 2009), there is remarkably little information in the literature concerning how these factors should be used when we interpret the achieved levels of various value items. For example, an improvement in the technical competencies of IS staff may be considered a positive progress, but when also accounting for the availability of comprehensive training programmes, financial incentives and an overall learnerfriendly firm culture, the level of improvement may turn out to be disappointing. In addition, patents achieved through IS-induced innovations need to be assessed in the context of whether other competitors have filed similar patents, what can be done with the granted patents with regard to competitive advantage, and whether national or supranational (e.g. European Union) laws or regulations have changed and thereby facilitated 
or impeded the patenting of innovations. Similarly, IS-induced changes in market-oriented measures, such as Tobin's q, need to be assessed in the context of the market performance of competitors and general stock market conditions. Clarifying these issues is highly important with regard to detecting and explaining achieved competitive advantage. To sum up, the evaluation of IS business value should be context-specific (Sylla \& Wen, 2002; Alshawi et al, 2003).

In order to operationalise this requirement, two questions need to be answered in future research: first, it needs to be clarified which firm, industry and country factors are to be considered for which value items (mapping of factors to value items). A good starting point would be to draw on the aforementioned factors that are assumed to have a causal nature with value items. Regarding firm factors, our research agenda reconceptualises a substantial set of factors as value items themselves, or more specifically, as value items of IS innovation, change in IS capabilities and socio-organisational change. However, there remain other firm factors that should be analysed in future research, including firm size, firm culture and geographical dispersion of firm units. Important industry factors include regulation, competitiveness, technological change, IS standards (Melville et al, 2004) and time-sensitiveness (Kraemer et al, 2000). In addition, when IS spans firm boundaries, then interorganisational relationships with trading partners can play a significant role (Mukhopadhyay et al, 1995; Chatfield \& Yetton, 2000; Williams \& Frolick, 2001; Melville et al, 2004; Banker et al, 2010). Country factors include the regulation of technology development and information industries, information infrastructure, and prevailing information and IT cultures. As Melville et al (2004, p. 297) note, [...] firms in developing countries face constraints in applying information technology in the areas of education, expertise, infrastructure, and culture (Jarvenpaa \& Leidner, 1998). Overall, we suggest the adoption of a broad perspective that accounts for political, regulatory, educational, social and cultural contexts (Jelassi \& Figon, 1994; Tam, 1998; Dewan \& Kraemer, 2000; Melville et al, 2004; Garud et al, 2006). The search for contextual factors should not be limited to explanatory factors. For example, although the IS innovation of competitors (industry factor) may have no causal impact on a firm's own IS innovation, for the final assessment of a firm's own IS innovation, what other firms have achieved in this regard can be relevant. Benchmarking achieved levels of IS innovation can help to predict the strategic position of both the firm itself and its competitors.

Second, it needs to be clarified how the assessment of value items should consider the (instantiations of) contextual factors identified in the previous step. For this purpose, we find the concept of 'states' useful as applied in decision theory (see, for example, Clemen, (1991)). In decision theory the outcomes of an action are assessed dependent on the environmental situation. We argue that this concept is not only useful in (ex ante) decison making but also in the (ex post) assessment of IS business value. States can be used as conceptual constructs of economic conditions, which are instantiations of environmental factors. For example, when assessing productivity (as a value item of process performance) in the context of the environmental factors 'competencies in process restructuring', 'average productivity gain of competitors' and 'increase in market demand', possible states $\mathrm{S} 1$ and $\mathrm{S} 2$ are $\mathrm{S} 1=$ (competencies in process restructuring $=$ 'high', average productivity gain of competitors $=2-5 \%$, increase in market demand $=$ $1-2 \%)$ and $\mathrm{S} 2==$ (competencies in process restructuring $=$ 'low', average productivity gain of competitors $=$ $0 \%$, increase in market demand $=5-10 \%)$. It is obvious that a firm's own productivity gain of $1 \%$ is less advantageous and less satisfactory in state S1 than in state S2.

The discussion of research thrust 1 already revealed the importance of using perceptual measures (Seddon, 1997; Chau et al, 2007), such as user satisfaction, the attitude towards technology use and a firm's strategic position, in the context of the evaluation of intangible value items. As perceptual measures are tied to subjective attitudes of the evaluators, the preferences of the respective evaluators finally affect the (perceived) business value. We find it important to note that the relevance of considering subjective preferences of stakeholders goes even beyond the evaluation of intangible value items. Even when 'hard' economic performance measures are applied, such as productivity and total shareholder return, different stakeholders interpret these values differently when they have partly conflicting interests and thus divergent preferences (Tallon et al, 2000; Chau et al, 2007). In order to account for this phenomenon, researchers can draw on the concepts proposed in utility theory (Fishburn, 1970). This discipline applies the concept of (subjective) preference functions, which map (objective) outcomes onto (subjective) utilities in accordance with the evaluators' preferences. For example, the utility can mirror how a manager values a $5 \%$ productivity gain in terms of competitive advantage. Future research would need to identify and compare preference functions for various stakeholders.

\section{Neglected disaggregation of IS investments}

Our literature review reveals deficiencies in knowledge of how specific IS assets contribute to various types of economic performance. These deficiencies are closely related to the fact that the existing IS literature suffers from ambiguity in the definition and conceptualisation of IS resources (Wade \& Hulland, 2004). Furthermore, most current conceptualisations of IS resources equate potentially heterogeneous investment allocations across firms by measuring total IS intensity. In order to account for these deficiencies, we formulate

Research thrust 3: How can total IS investments be disaggregated conceptually and empirically such that the 
impact of different types of investments on the economic performance of a firm can be determined?

To study this question, it is necessary to identify different types of IS assets that are accountable for different types of performance. From a conceptual point of view, we argue that a useful step towards disaggregation is a classification of IS assets, which goes beyond a simple, but inappropriate classification of IS as hardware, software, telecommunications and the services of IT personnel, as is often suggested in the literature (e.g. Whyte, 2010). One of the shortcomings of this classification is that it does not consider the purpose for which the asset is used: for example, a CRM system helps identify individual customer needs and ultimately increase revenue or even market share, while a video conference software helps avoid travel expenses and save time in negotiations with business partners. These business purposes (and the related IS investments) are hardly comparable in terms of how useful they are for a firm unless we account for the business goals of the respective firms. For example, while for mobile service providers knowledge about their customers is a key requirement to compete in the mobile communication market, a consulting company may aim at speeding up communication with customers. Consequently, it would seem reasonable to distinguish IS investments according to the respective business goals of firms. Aral \& Weill (2007, p. 766) suggest distinguishing [...] innovative vs noninnovative, strategic versus nonstrategic, and internally focused (e.g., process control, coordination, etc.) versus externally focused investments (customer satisfaction, relationship management, etc.). More generally, Weill (1992) and Weill \& Broadbent (1998) suggest disaggregating IS assets by categorising firms' IS investments into a portfolio of infrastructure, transactional, informational and strategic assets. Regarding the latter, a promising approach would be to draw on the RBV (Wernerfelt, 1984; Barney, 1991) in order to account for the strategic purposes of IS resources; we discuss the potential of the RBV of the firm further in the following subsection, where we address value generation processes. This perspective is supported by Aral \& Weill (2007), who argue that the impact of IS on organisational performance can be captured only if we investigate how firms allocate investments across different types of IS assets and how these assets contribute to building and sustaining valuable, scarce and difficult-toimitate resources. However, research in this regard is in its infancy (Wade \& Hulland, 2004).

Beyond the aforementioned conceptual issues in disaggregating IS investments, we need to keep in mind that the practical benefit of any classification depends on how well it can be applied in practice. A key challenge in practice will be the assignment of IS assets to particular asset classes, therefore we need to define methodologies that account for potential ambiguities in this assignment. Any conceptual disaggregation of IS assets should envision this practical issue. A second practical problem for empirical research is related to the availability of data: while firms' expenses in hardware, software and infrastructure may be available for specific firms, industries or economies, their general availability across these boundaries is often limited. Thus, it is almost impossible to measure these inputs accurately (Whyte, 2010). As a consequence, today we cannot expect to get even more fine-grained information on IS investments, which would be necessary in order to account for infrastructure, transactional, informational and strategic assets, for example. In order to account for this deficiency, it would be useful for researchers to go into firms and collect and evaluate these data in case studies. The availability of a comprehensive data set provided by firms or acquired by researchers would be even more useful.

Researchers have convincingly argued that the disaggregation of IS investments into single IS assets should be accompanied by accounting for linkages between them (Aral \& Weill, 2007; Cho \& Shaw, 2009). However, while synergy and diversification have been intensively discussed in other areas, such as in the strategy literature (Amihud \& Lev, 1981; Christensen \& Montgomery, 1981; Rumelt, 1982; Palepu, 1985; Robins \& Wiersema, 1995; Farjoun, 1998; Miller, 2004; Tanriverdi \& Venkatraman, 2005), there is hardly any mention of synergies of IS investments in the IS literature.

Research thrust 4: How can the disaggregation of total IS investments account for synergies and complementarities of IS assets?

This research thrust will require identifying opportunities of synergies and complementarities of IS assets. Synergies of IS assets occur when the benefit of jointly using several IS assets is higher than the sum of the benefits of each of the single IS assets. The discussion of potential synergies of IS investments is almost absent in the IS business value literature, and we found only the work of Cho \& Shaw (2009), who draw on portfolio selection theory to optimise IS investments across business units. While their focus is on decision making in multiple business units, our focus lies on the explanation of how IS assets create synergies at the firm level. Thus, we suggest a different approach to identify synergies: we argue that synergies occur primarily when IS assets serve the same business objectives. Following this logic, we need to develop methodologies that allow us to identify a mapping between IS assets and business objectives. These objectives may have a competitive orientation, but they can also target other aspects, such IS capabilities, socio-organisational capabilities, firm culture and legal compliance.

In the management literature, one key concept in operationalising business objectives is 'critical success factors' (CSF) (Rockart, 1979; Boynlon \& Zmud, 1984), which are factors that ensure that business objectives are 


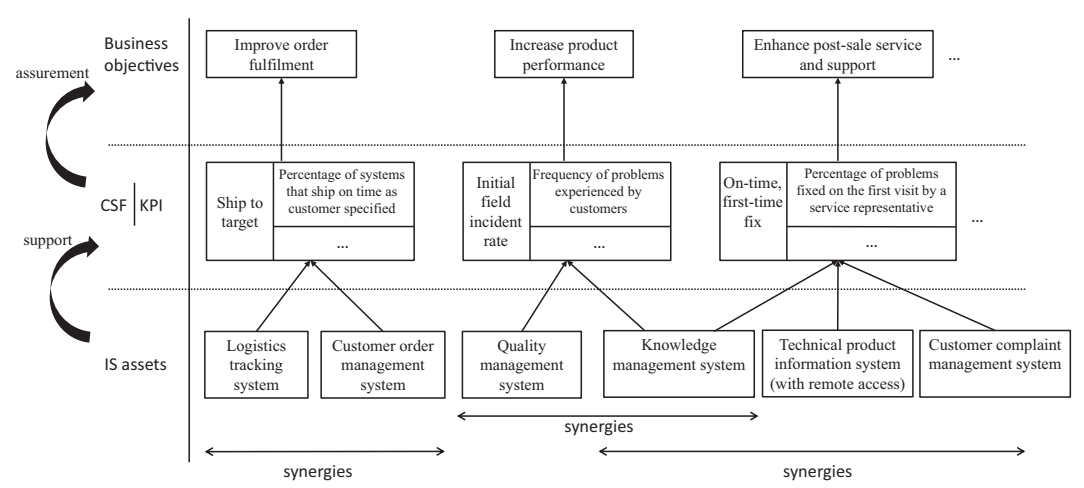

Figure 5 Relationship between business objectives, CSF/KPI, and IS assets; based on Reicheld \& Schefter (2000).

achieved. These business objectives can comprise both profit and non-profit objectives (Rockart, 1979; Boynlon $\&$ Zmud, 1984), so we regard the concept of CSF as useful for our purpose. In the context of developing an IS asset portfolio, CSF are often used to derive information requirements, which finally drive the selection of IS assets (Chaffey \& Wood, 2005, p. 314ff; Laudon \& Laudon, 2005, p. 448ff). We see the applicability of CSF in a broader context and argue that they can also be used to derive requirements in other IS-supported activities, including business process support, and intra- and interorganisational communication. While the first step is the assignment of CSF to business goals, the second step is assigning IS assets to CSF. As CSF can still be at a high level, we suggest the further operationalisation of CSF with key performance indicators (KPI), which are measures of CSF (Chaffey \& Wood, 2005, p. 314f). CSF and associated KPI can then be used to identify those IS assets that jointly support the specific CSF and can thus provide synergies. Figure 5 illustrates the relationships between business objects, CSF/KFI and IS assets with an example that draws on the relationships between loyalty drivers and measures to assess their success at Dell (Reicheld \& Schefter, 2000). In this example, we assume that the CSF 'Ship to target' can be supported by a logistics tracking system, which helps to detect possible delays in shipping the system to the customer, and a customer management order system, which helps the timely processing of customer orders. The CSF 'Initial field incident rate' can be supported by a (product) quality management system and a knowledge management system, which stores and provides knowledge on how to avoid quality problems. If this knowledge management system also stores knowledge on how such problems can be solved once they occur, then the system also contributes to another CSF 'On-time, first-time fix'. Together with a technical product IS with mobile accessibility for technicians, and a customer complaint management system, which provides for detailed comments by customers regarding the particular problems that occur, the three systems finally support the business objective 'Enhance post-sale service and support'.
The scenario shows that the relationship between CSF and IS assets is an (m:n) relationship, that is a single CSF can be supported by several IS assets (relationship A), and a single IS asset can serve several CSF (relationship B). Relationship A offers the opportunity for synergies of IS assets regarding the creation of value (in terms of supporting a CSF). We refer to this as 'super-additive IS value synergy'. Relationship B offers the opportunity for synergies of IS assets regarding cost saving. For example, a knowledge management system that accounts for knowledge about both how to avoid quality problems and how to solve quality problems is probably less expensive than two dedicated knowledge management systems. We refer to this type of synergy as 'sub-additive IS cost synergy'. The related terms 'super-additive value synergy' and 'subadditive cost IT synergy' are used by Cho \& Shaw (2009) in the context of synergies between two IT investment units. However, we adopt the notions here as they are also appropriate for describing synergies in our context.

We see two key advantages of following the approach displayed in Figure 5 in future research on synergies and complementarities of IS assets: (1) It allows a systematic and generally applicable identification of (sets of) IS assets, which serve the same business objective and thus have the potential to create synergies. (2) CSF are shaped by the firm, the industry and the national environment (Laudon \& Laudon, 2005, p. 448f) so that they can account for the various environmental factors modelled in our research agenda. This approach allows the explanation of differences in synergy generation (and thus in economic performance) between firms that invest in the same set of IS assets.

Following the suggested CSF-based approach, future research would need to pay attention to answering two research questions: (1) How can CSF/KPI be mapped on supporting IS assets? (2) When does which type of synergy of IS assets occur?

\section{IS business value creation process as grey box}

Our review of the literature reveals that researchers, particularly those drawing on (socio-) organisational theories, have identified IS capabilities and socio-organisational 
capabilities as complementarities that mediate the impact of (investments in) IS in supporting the competitive goals of a firm (DeSanctis \& Poole, 1994; Rowe, 1994; Orlikowski, 1996; Avgerou, 2001; Aral \& Weill, 2007; Kane \& Alavi, 2007; Mutch, 2010; Rai \& Tang, 2010; Mithas et al, 2011). We thus distinguish internal value (complementarities) from competitive value, which is directly market-oriented (e.g. protection of resources, innovations, market share). Analysing the former, we find that the process of generating internal value, based on the relationships between IS assets and various complementarities, has not been sufficiently explored. Consistent with Zammuto et al (2007) and Orlikowski \& Iacono (2001), we argue that these relationships are not static and can thus be explained more appropriately when accounting for time-variant changes. Consequently, we suggest a perspective that accounts for both static and dynamic aspects.

Research thrust 5: How, why and when do IS assets, IS capabilities and socio-organisational capabilities affect each other and jointly create internal value?

To study this research question, we need to conceptualise how capabilities can manifest as intangible values and to explain interdependencies between IS assets (for the need for operationalisation, see research thrusts no. 3 and 4), IS capabilities, and socio-organisational capabilities in terms of their mutually reinforcing character. Regarding the conceptualisation of IS capabilities, we find the approach of Aral \& Weill (2007) useful: they draw on the work of Nelson \& Winter (1982) and distinguish IS competencies (IS skills and IS management quality) and IS practices (culture of IS use) as 'interlocking systems' that complement IS, based on the RBV and evolutionary economics. It should be noticed that Aral \& Weill (2007) also include 'digital transactions' and 'Internet architecture', but following Bourdieu's theory of practice (Bourdieu, 1977), we argue that these parts should not be subsumed under practices. To sum up, future research would need to investigate how competencies and practices influence each other and how these IS capabilities develop over time (change in IS capabilities).

In addition to IS-related organisational capabilities, other socio-organisational capabilities have been discussed intensively in the context of IS and organisational research (DeSanctis \& Poole, 1994; Rowe, 1994; Fulk \& DeSanctis, 1995; Orlikowski, 1996; Shin, 1997; Whittington et al, 1999; Bannister \& Remenyi, 2000; Brynjolfsson \& Hitt, 2000; Devaraj \& Kohli, 2000; Avgerou, 2001; Irani \& Love, 2001; Irani, 2002; Pinsonneault \& Kraemer, 2002; Oz, 2005; Aral \& Weill, 2007; Kane \& Alavi, 2007; Leonardi, 2007; Zammuto et al, 2007; Mutch, 2010). Important parts are deemed (intra- and interorganisational) processes, practices and structures, all of which develop over time, thereby creating socio-organisational change. However, researchers have been remarkably silent concerning the questions of how and when socioorganisational change induces changes in IS capabilities and vice versa; the only pertinent studies we found were those of Rai \& Tang (2010) and Mithas et al (2011), who operationalise socio-organisational capabilities by distinguishing customer management capability, process management capability and performance management capability). Mithas et al (2011) find empirical evidence that all three capabilities are positively correlated with IS capabilities (more specifically, with information management capabilities). However, the existence of correlations between constructs does not necessarily imply the existence of causal links between these constructs. Thus, we argue that future research should analyse the causal impact of each of the capability types on IS capabilities as well as the joint causal impact of all three capability types.

In contrast, a substantial body of contributions addresses the relationship between socio-organisational capabilities and IS innovation. If we regard the latter as a construct that models time-variant dynamics of IS assets in order to account for the fact that different assets are subject to different speeds of IS innovation (Whyte, 2010), we can conceptually merge the static perspective on IS assets with the dynamic perspective on how their development (IS innovation) interacts with socioorganisational capabilities (see Figure 3). This interaction has been studied intensively, but it needs further attention due to conflicting results: a substantial body of research attests a symbiotic relationship between IS innovation and socio-organisational change (Ciborra \& Lanzara, 1994; Rowe, 1994; Orlikowski \& Walsham, 1996; Orlikowski, 1996; Whittington et al, 1999; Avgerou, 2001; Aral \& Weill, 2007; Kane \& Alavi, 2007; Leonardi, 2007; Zammuto et al, 2007), which is consistent with results from various streams and concepts of socio-technical research, including the duality of technology (Daft, 1978; Orlikowski, 1992; DeSanctis \& Poole, 1994), and actor networks (Callon, 1991; Latour, 1991; Akrich, 1992). Avgerou (2001) provides a good overview of this research and stresses that value creation is a social construction. In contrast, another stream of research (although weaker in terms of literature contributions) questions the symbiotic relationship. For example, Avgerou (2000) adopts an institutionalisation perspective and finds empirical evidence that '[i]t is misleading to consider IT an enabler to or a result from the efforts of organizational change. [...] IT innovation proceeds in a self-fulfilling manner, relying mainly on its own institutional forces'(p. 242). Based on a case study, the author argues that IS has become a 'rational myth', using the term suggested by Meyer \& Rowan (1991) (p. 238). Another issue that questions the symbiotic relationship between IS innovation and socioorganisational change is related to organisational structures. While some studies find that IS innovation has been associated with the emergence of new organisational forms replacing the hierarchical bureaucratic structure (Drucker, 1988; Powell, 1990; Bjorn-Andersen \& Turner, 


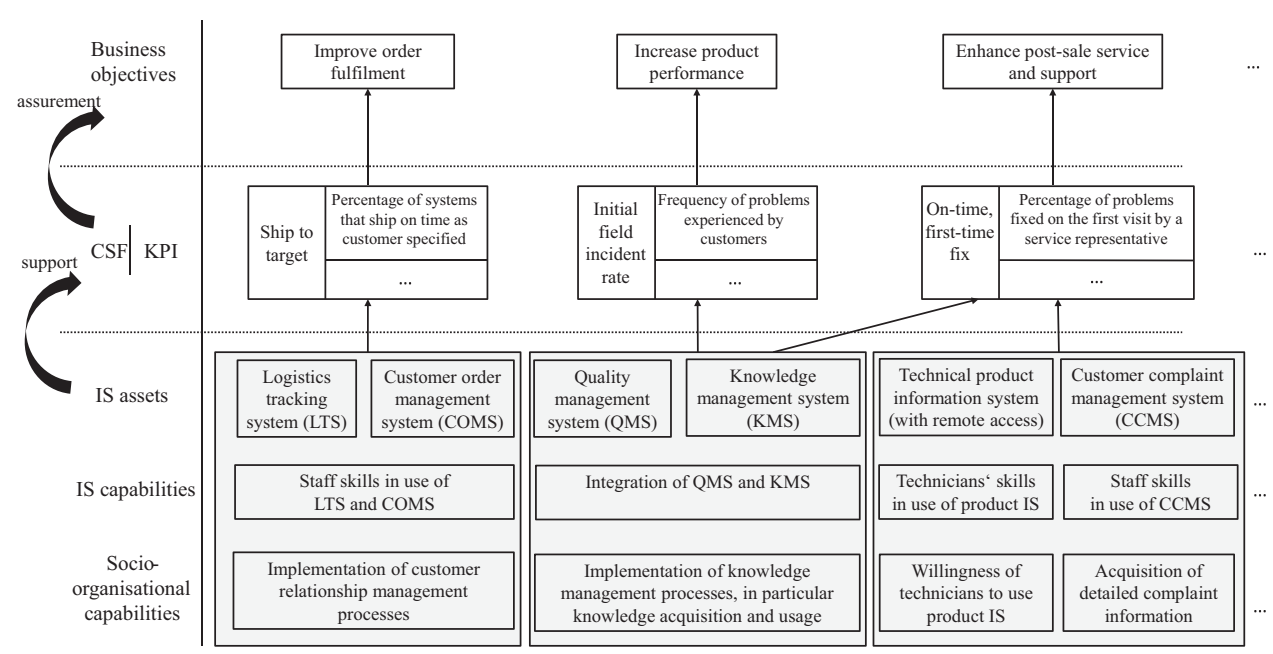

Figure 6 Relationship between business objectives, CSF/KPI, IS assets, IS capabilities and socio-organisational capabilities.

1994), Applegate (1994) reports that her continuing research on IS and organisational forms suggests the persistence of the hierarchical structure, rather than its replacement.

Future work needs to resolve the aforementioned contradictions and clarify the relationship between IS innovation and socio-organisational change. We argue that such research would need to differentiate the relationships between the various types of IS assets and socio-organisational capabilities (practices, intraorganisational processes, inter-organisational processes, and structures), and to consider the development of these relationships over time. The classification of different types of impact may follow the differentiation of Pinsonneault \& Kraemer (2002), who distinguish between the 'facilitate effect' and the 'cause effect'.

Finally, the relationship between IS innovation and change in IS capabilities has not received much attention in the literature although both are considered key components in accomplishing organisational tasks (Aral $\&$ Weill, 2007). The importance of analysing the relationship becomes evident when we draw on the RBV and argue that the actual benefit of IS assets is not their pure availability in a firm (IS assets can rapidly become commodities), but their much more difficult-to-imitate interplay with capability development and learning opportunities tied to firms' specific asset positions (Dierickx \& Cool, 1989; Cohen \& Levinthal, 1990). We suggest focusing on this relationship in future research.

Beyond the explanation of how internal capabilities and intangible value are created, IS business value research must account for how competitive value is cocreated through IS and internal values. As the discussion of IS value generation in the previous section reveals, the literature acknowledges that this effect is substantial and can result in competitive value that manifests in many ways, including the protection of resources, innovations (e.g. protected through patents), market performance and accounting performance. However, research still lacks an explanatory component concerning this phenomenon.

Research thrust 6: How, why and when do IS assets, IS capabilities and socio-organisational capabilities jointly create competitive value, thus performing a value creation process?

This research thrust will require explaining how specific types of competitive value are supported or even caused by various IS assets and internal value items. Our approach is consistent with the conceptualisation of Mithas et al (2011), who propose a two-stage model with the information management capability as a focal construct and organisational capabilities as the mediators between information management capability and firm performance.

We see several promising research paths. One approach is to validate the hypothesis of Aral \& Weill (2007), who claim that '[f]irms' total IT investment is not associated with performance, but investments in specific IT assets explain performance differences along dimensions consistent with their strategic purpose' (p. 763). While the authors regard strategies at a high level (e.g. cost leadership or innovation), we argue that this phenomenon should also be studied at a more concrete level. Consistent with the analysis of synergies of IS assets in creating value (see research thrust 4), we argue that the use of business objectives operationalised through CSF and KPI is a good starting point for analysing how IS assets, IS capabilities and socio-organisational capabilities jointly contribute towards achieving competitive value. More precisely, future research needs to identify bundles of IS assets, IS capabilities and socio-organisational capabilities for each of the CSF. Figure 6 exemplifies this approach by 
extending Figure 5. In our scenario we hypothesise, for example, that the CSF 'Ship to target' not only needs to be supported by a logistics tracking system and a consumer order management system, but also by staff skills in using these systems and by the implementation of CRM processes. While the levels of business objectives and CSF/KPI are part of a real world example (Reicheld \& Schefter, 2000), the levels of IS assets and complementarities are fictional and would need to be empirically analysed in future research.

A second approach is related to access to external resources. For example, if acquiring and protecting access to external information resources, such as media content, real-time stock data, or technical information on suppliers' products, is a key success factor in sustaining a firm's competitiveness, then investments in inter-organisational IS and the development of capabilities to integrate them in business processes seem reasonable. A profound theoretical underpinning of these arguments is provided by the 'Resource Dependence Theory' (RDT) (Pfeffer \& Salancik, 1978), according to which [...] actors lacking in essential resources will seek to establish relationships with (i.e., be dependent upon) others in order to obtain needed resources. Also, organizations attempt to alter their dependence relationships by minimizing their own dependence or by increasing the dependence of other organizations on them (Schneberger \& Wade, 2010). While the RDT theory has been applied in the general IS literature - for a good overview see the list of references provided by Schneberger \& Wade (2010) - we are not aware of studies that use RDT to explain the (potential of the) creation of IS business value through IS. Thus, we suggest that future IS business value research make use of the RDT.

A third option is that the strategic-oriented perspective on IS is complemented with research efforts in the field of IS governance, which deals with the strategic alignment of business and IS and has only recently begun to be investigated by scholars (Schwarz \& Hirschheim, 2003; Raghupathi, 2007; Ali \& Green, 2012; Ho et al, 2011). This option is supported by the empirical findings of Avison et al (2006) and Nelson (2007), who identified managerial IS unconsciousness, failure in IS governance and insufficient risk management as widely occurring mistakes that cause the failure of IS projects and, in some cases, even bankruptcy of companies.

A fourth stream of research should target unanticipated consequences, which can be positive and/or negative, result directly or indirectly from IS use, and which can occur despite or because of IS investments. Markus \& Robey (2004) provide a rich set of theoretical explanations (see the subsection 'IS business value creation process as grey box'), but an integrated theory still needs to be developed and empirically validated.

A fifth perspective on the research thrust can be adopted through the 'Resource-based View' (RBV) (Wernerfelt, 1984; Barney, 1991), which argues that durable competitive advantage emerges from unique combinations of resources (Grant, 1996) that are economically valuable, scarce and difficult to imitate (Barney, 1991). The RBV on IS assets conceptualises IS assets as resources and identifies the strategic purpose of IS resources for the firm (Wade \& Hulland, 2004). Consistent with Aral \& Weill (2007), we argue that the impact of IS and complementing capabilities on a firm's competitive position can be captured only if we investigate how firms' IS allocations and firms' capabilities (Powell \& Dent-Micallef, 1997) jointly contribute to building and sustaining resources. This (more comprehensive) perspective might resolve the alleged contradictory results concerning the strategic relevance of IS. As a consequence, even when IS assets are identified as imitable resources that are perfectly mobile across organisational boundaries, the bundle consisting of these assets and complementary capabilities may form a difficult-to-imitate resource. However, research in this regard is not well developed.

Finally, we argue that future research needs to acknowledge concerns regarding the durability of competitive advantages that are induced through such bundles. As in the case of internal value, we argue that also the perspective on competitive value needs to account for time-variance and that such value is eroded over time, depending on competitors' ability and the speed with which IS assets and capabilities are imitated by competitors. Rowe $(1994$, p. 29) argues that $[. .$.$] competitive$ advantage can only be achieved during periods when there is uncertainty concerning technology and when organizational innovation is being introduced. We thereby question Grant's (1996) hypothesis of 'durable competitive advantage' in the context of IS business value, and we argue that future research needs to investigate the time dimension of competitive value.

\section{Summary of research agenda}

Table 3 summarises the key components of the proposed research agenda.

\section{Potential for further research}

The research agenda presented in the previous section proposes paths for closing three research gaps: (a) ambiguity and fuzziness of the 'IS business value' construct, (b) neglected disaggregation of IS investments, and (c) IS business value creation process as grey box. While we believe that these research gaps and the related deficiencies (see Table 3) belong to the most severe issues in current IS business value research and that our research agenda includes the most urgent research thrusts, we also see further potential for research:

(1) Our research is intrinsically tied to the ex post, firmlevel perspective on IS business value. This view limits the applicability of the synthesised IS business value model and the derived research agenda in several regards: (i) They are not tailored to specific sectors. Such work is provided for the manufacturing sector (Banker et al, 2006), the banking sector (Beccalli, 2007; Casolaro \& Gobbi, 2007; Senadheera et al, 
Table 3 Agenda for IS business value research

\begin{tabular}{ll}
\hline Research gaps & Research thrusts \\
\hline Ambiguity and & How can we yield a comprehensive, \\
fuzziness of the & consistent and precise understanding \\
'IS business value' & of the multifaceted construct 'IS business \\
construct & value'?
\end{tabular}

How can the assessment of (internal and competitive) business value account for the context of evaluation, and in particular the firm, industry and country environment and the preferences of evaluators?

How can total IS investments be disaggregated conceptually and empirically such that the impact of different types of investments on the economic performance of a firm can be determined?

How can the disaggregation of total IS investments account for synergies and complementarities of IS assets?

How, why and when do IS assets, IS capabilities and socio-organisational capabilities affect each other and jointly create internal value?

How, why and when do IS assets, IS capabilities and socio-organisational capabilities jointly create competitive value, thus performing a value creation process?

Research paths

- Disaggregation and operationalisation of four types of IS business value (based on suggested value taxonomy).

- Identification of value items with which the respective value can be measured.

- Use of objective and perceptual measures.

- Identification and development of methodologies that allow the measurement of value items.

- Identification of (value item specific) environmental factors and their impact on the ultimate economic meaning of value items.

- Use of 'states' as conceptual constructs of economic conditions, which are instantiations of environmental factors.

- Consideration of subjective preferences of stakeholders.

- Identification of preference functions of stakeholder (utility theory).

- Conceptual development of IS asset classification according to the objectives of the firm.

- Suggestion of methodologies that account for potential ambiguities in classification.

- Case studies in firms in order to trace and evaluate investments in particular IS assets.

- Identification of synergy opportunities of IS assets by means of business objectives, critical success factors and key performance indicators.

- Distinction between 'super-additive IS value synergy' and 'subadditive IS cost synergy'.

- Interdependencies between particular IS capabilities, competencies and practices; development of IS capabilities over time (change in IS capabilities).

- Impact of socio-organisational change on changes in IS capabilities; consideration of three types of socio-organisational capabilities: customer management capability, process management capability and performance management capability.

- Future work needs to resolve contradictory results in the literature regarding the relationship between IS innovation and socioorganisational change.

- Relationship between IS innovation and change in IS capabilities needs to be investigated in order to understand how IS assets and innovation contribute to building and sustaining valuable, scarce and difficult-to-imitate resources.

- Identification of complementarities of IS assets, IS capabilities and socio-organisational capabilities by means of business objectives, critical success factors and key performance indicators.

- Protection of access to resources, decrease in dependence of own firm on other firms, and increase in dependence of other firms on own firm through inter-organisational IS (Resource Dependence Theory).

- Competitive value of IS and capabilities manifests in performance differences along dimensions consistent with their strategic purpose (Resource-based view, IS governance).

- IS use can have unanticipated consequences. The development of an integrated explanatory theory can draw on the multidisciplinary theoretical input of Markus \& Robey (2004).

- Erosion of competitive value over time depends on ability and speed with which IS assets and capabilities are imitated by competitors. 
2011) and the insurance sector (Harris \& Katz, 1991; Neirotti \& Paolucci, 2007), for example. (ii) Our work does not address national economies or specific countries (see, for example, Poon \& Davis, 2003; Swierczek \& Shrestha, 2003; Senadheera et al, 2011), nor does it provide a research agenda for studying (differences between) developed and developing countries (see, for example, Dedrick et al, 2003; Lin \& Chiang, 2011). (iii) The model and the derived research agenda are not adequate for combining research at different levels, as suggested in the literature (DeLone \& McLean, 1992; Kohli \& Grover, 2008; Paré et al, 2008).

(2) Recent work on green IT and energy informatics shifts the focus of IS value towards ecological goals. For example, Watson et al (2010) and Loos et al (2011) argue for applying IS thinking and skills to reduce energy consumption and $\mathrm{CO}_{2}$ emissions. This research is linked to the sustainability literature, which identifies three goals: eco-efficiency, eco-equity and eco-effectiveness (Dyllick \& Hockerts, 2002). We acknowledge that adding the ecological perspective to the IS business value discussion in future studies will be useful in identifying IS benefits that are complementary to process, market and/or accounting performance.

(3) Social media, such as Facebook, Twitter and LinkedIn, are a new phenomenon that bears the potential to support companies in various activities. For example, they can be used for viral marketing (Hinz et al, 2012), market research (Dellarocas et al, 2010), recruiting (Weitzel et al, 2009), and CRM (Derham et al, 2011) and customer interaction (Senadheera et al, 2011). However, the use of social media is relatively new to many organisations, which are still experimenting when they make their initial forays into social media (Nair, 2011). It seems that companies have only limited knowledge on how to exploit the potentials of social media. We advocate investigations into how companies can gain business value from social media (see, for example, the work of Culnan et al, 2010).

(4) Our paper does not focus on the relationship between IS investments and economic risk. IS investments bear economic risks due to the uncertainty of the future and states (McFarlan, 1981; Mata et al, 1995), and are even regarded as being substantially riskier than non-IS investments, as measured by their relative contributions to the overall riskiness of the firm (Dewan et al, 2007). While risk in the context of IS investment decision making (ex ante evaluation) has received a little attention (Sylla \& Wen, 2002; Au \& Kauffman, 2003; Benaroch et al, 2007; Dewan et al, 2007), both the creation and the reduction of risk through IS investments has been neglected. However, this neglect can result in ignoring the essential impact of IS investments. For example, when an online broker invests in a load balancing system, which decreases the probability of broker service unavailability, the expected loss of revenue due to server downtimes is reduced. On the other hand, the deployment of a network-based CRM system creates risk with regard to the confidentiality of customer data due to attacks from hackers. Despite some recent contributions on the impact of IS on economic risk (e.g. Dewan \& Ren, 2007; Hannu, 2008), this subfield of IS business value research needs more attention as Dewan et al already noted in 2007: [The] consideration of risk is virtually absent in the growing literature on the returns on IT investment, even though the risks are widely recognized (p. 1829).

(5) The synthesis of literature findings (and the subsequent derivation of research deficiencies) is mainly based on journals, databases and conference proceedings (see Appendix B) that are related to the IS discipline and to organisation science. An in-depth investigation of the literature in other disciplines, such as sociology, psychology and computer science, may result in further research streams.

\section{Concluding remarks}

Accounting for enduring doubts about the value of IS investments, this paper aims at pushing forward research on IS business value by synthesising existing knowledge, identifying research gaps and proposing a research agenda. On the basis of a comprehensive literature review, which includes more than 200 research papers and 20 literature reviews, we showed that the literature has generated substantial knowledge of performance measures, contextual factors, lag effects and the impact of IS investments on market performance, accounting performance and productivity. However, results in these subfields have not explained sufficiently how, why and when IS investments create business value. Future research needs to close three research gaps by (a) resolving the ambiguity and fuzziness of the 'IS business value' construct, (b) disaggregating IS investments, and (c) opening the grey box of the IS business value creation process. In order to overcome these limitations and provide starting points for research activities, we suggest a research agenda, including research thrusts and concrete research paths.

We regard (IS business value) theory building and testing as one of the key challenges of future research. To approach this goal, we deem it necessary to investigate causal relationships between capabilities, IS assets and competitive value items. Such causal relationships are indicated by the arrows between value items in the graphical representation of our research agenda (Figure 3). We contemporaneously acknowledge that a theory on IS business value should help to explain dynamic phenomena. Thus, our research agenda also accounts for questions related to time-dependent relationships (indicated through elliptic arrows in Figure 3). While the former research paths are aligned with variance theories, which incorporate independent variables that cause variation in dependent variables, the latter paths are linked to process 
theories, which target dynamic phenomena (Webster \& Watson, 2002, p. xix). Our research agenda thereby accounts for the argument that $[\ldots]$ many of the best theories are hybrids, combining the best qualities (Newman \& Sabherwal, 1991; DiMaggio, 1995, p. 392).

\section{About the author}

Guido Schryen holds a position as full professor of Information Systems Research at the University of Regensburg, Germany. He received a doctorate in information systems and earned a post-doctorate degree (habilitation) at the RWTH Aachen University. He was visiting researcher at

\section{References}

AGARWAL R and LUCAS HC (2005) The information systems identity crisis: focusing on high-visibility and high-impact research. MIS Quarterly 29(3), 381-398.

AKRICH M (1992) The description of technical objects. In Shaping Technology, Building Society: Studies in Sociotechnical Change (BIJKER W and LAW J, Eds), pp 205-224, MIT Press, Cambridge, MA.

ALI S and GREEN P (2012) Effective information technology (IT) governance mechanisms: an IT outsourcing perspective. Information Systems Frontiers 14(2), 179-193.

AlPAR P and KIM M (1990) A microeconomic approach to the measurement of information technology value. Journal of Management Information Systems 7(2), 55-69.

ALSHAWI S, IRANI Z and BALDWIN LP (2003) Benchmarking information technology investment and benefits extraction. Benchmarking - An International Journal 10(4), 414-423.

AMIHUD $Y$ and LEV B (1981) Risk reduction as managerial motive for conglomerate mergers. Bell Journal of Economics of Innovation \& New Technology 12(Autumn), 605-617.

ANDRIOLE SJ (2010) Business impact of Web 2.0 technologies. Communications of the ACM 53(12), 67-79.

APPLEGATE LM (1994) Managing in an information age: transforming the organization for the 1990s. In Transforming Organizations with Information Technology (Baskerville R, SMithson S, NGwenyama O and DeGross II, Eds), pp 15-94, North-Holland, Amsterdam, The Netherlands.

ARAL S, BRYNJOLFSSON E and VAN ALSTYNE M (2007) Information, Technology and Information Worker Productivity Task Level Evidence. National Bureau of Economic Research, Cambridge, MA, US.

ARAL S and WEILL P (2007) IT assets, organizational capabilities, and firm performance: how resource allocations and organizational differences explain performance variation. Organization Science 18(5), 763-780.

ARMSTRONG C and SAMBAMURTHY V (1999) Information technology assimilation in firms: the influence of senior leadership and IT infrastructures. Information Systems Research 10(4), 304-327.

ATIS (2007) ATIS Telecom Glossary 2007. Alliance for Telecommunications Industry Solutions [WWW document] http://www.atis.org/ glossary/.

AU YA and KAUFFMAN RJ (2003) What do you know? Rational expectations in information technology adoption and investment. Journal of Management Information Systems 20(2), 49-76.

AVGEROU C (2000) IT and organizational change: an institutionalist perspective. Information Technology \& People 13(4), 234-262.

AVGEROU C (2001) The significance of context in information systems and organizational change. Information Systems Journal 11(1), 43-63.

AVISON D, GREGOR S and WILSON D (2006) Managerial IT unconsciousness. Communications of the ACM 49(7), 89-93.

\section{Acknowledgements}

I am grateful to the Editor-in-Chief, the Associate Editor and the anonymous reviewers, who all provided many valuable comments that helped to improve the paper. I also thank Rachel Teear for her editorial assistance.
Stanford University, ICSI (Berkeley), QUT Brisbane and The Information Systems Security Research Center (ISSRC, University of Oulu, Finland). His fields of interest cover quantitative decision support (operations research), benefits of information systems and services, and IT security.
AVISON D and WILSON D (2002) IT failure and the collapse of One.Tel. In Information Systems: The E-Business Challenge (Traunmuller R, Ed.), pp 31-46, Kluwer Academic Publishers, Amsterdam, The Netherlands.

AYAL M and SEIDMANN A (2009) An empirical investigation of the value of integrating enterprise information systems: the case of medical imaging informatics. Journal of Management Information Systems 26(2), 43-68.

BAlLY MN (1986) What has happened to productivity growth? Science 234(4775), 443-451.

BAKER J, SONG J and JONES D (2008) Refining the IT business value model: evidence from a longitudinal investigation of healthcare firms. In Proceedings of the International Conference on Information Systems. Paris, France, Association for Information Systems, 14-17 December.

BAKOS JY (1987) Dependent variables for the study of firm and industrylevel impacts of information technology. In Proceedings of the International Conference on Information Systems (Gallegos L, Welke R and Wetherbe JC, Eds), pp 10-23, The Society for Information Management, Pittsburgh, PA.

BAKOS JY and NAULT BR (1997) Ownership and investment in electronic networks. Information Systems Research 8(4), 321-341.

BANKER R, BARDHAN I, CHANG H and LIN S (2006) Plant information systems, manufacturing capabilities, and plant performance. MIS Quarterly 30(2), 315-337.

BANKER RD, CHANG H and KAO Y-C (2010) Evaluating cross-organizational impacts of information technology - an empirical analysis. European Journal of Information Systems 19(2), 153-167.

BANNISTER F and REMENYI D (2000) Acts of faith: instinct, value and IT investment decisions. Journal of Information Technology 15(3), 231-241.

BARNEY JB (1991) Firm resources and sustained competitive advantage. Journal of Management 17(1), 99-120.

BarUa A, KRIEBel CH and MukHopadhyay T (1995) Information technologies and business value - an analytical and empirical investigation. Information Systems Research 6(1), 3-23.

BARUA A, LEE CHS and WHINSTON AB (1996) The calculus of reengineering. Information Systems Research 7(4), 409-428.

BECCALLI E (2007) Does IT investment improve bank performance? Evidence from Europe. Journal of Banking \& Finance 31(7), 2205-2230.

Belleflamme P (2001) Oligopolistic competition, IT use for product differentiation and the productivity paradox. International Journal of Industrial Organization 19(1-2), 227-248.

BENAROCH M, JEFFERY M, KAUFFMAN RJ and SHAH S (2007) Option-based risk management: a field study of sequential information technology investment decisions. Journal of Management Information Systems 24(2), 103-140. 
BENAROCH M and KAUFFMAN RJ (1999) A case for using real options pricing analysis to evaluate information technology project investments. Information Systems Research 10(1), 70-86.

BERGHOUT E and RENKEMA T (1997) Evaluating information systems investment proposals: a comparative review of current methodologies. Information and Software Technology 37(1), 1-13.

BERNDT ER and MORRISON Cl (1995) High-tech capital formation and economic performance in U.S. manufacturing industries: an exploratory analysis. Journal of Econometrics 65(1), 9-43.

BHARADWAJ A, BHARADWAJ SG and KONSYNSKI BR (1999) Information technology effects on firm performance as measured by Tobin's $q$ Management Science 45(7), 1008-1024.

BharadWAJ A, KeIL M and MAHRING M (2009) Effects of information technology failures on the market value of firms. The lournal of Strategic Information Systems 18(2), 66-79.

BHARADWAJ AS (2000) A resource-based perspective on information technology capability and firm performance: an empirical investigation. MIS Quarterly 24(1), 169-196.

BHATT GD and Grover V (2005) Types of information technology capabilities and their role in competitive advantage: an empirical study. Journal of Management Information Systems 22(2), 253-277.

BJORN-ANDERSEN N and TURNER JA (1994) Creating the twenty-first century organization: the metamorphosis of Oticon. In Transforming Organizations with Information Technology (BASKERVILLE R, SMITHSON S and NGwenYAMA O, Eds), pp 379-394, North-Holland, Amsterdam, The Netherlands.

BOURDIEU P (1977) Outline of a Theory of Practice. Cambridge University Press, Cambridge, New York.

BOYNLON AC and ZMUD RW (1984) An assessment of critical success factors. Sloan Management Review 25(4), 17-27.

BRESNAHAN TF， BRYNIOLFSSON E and HITT LM (2002) Information technology, workplace organization, and the demand for skilled labor: firm-level evidence. Quarterly Journal of Economics 117(1), 339-376.

BRYNJOLFSSON E (1993) The productivity paradox of information technology. Communications of the ACM 36(12), 66-77.

BRYNJOLFSSON E (1996) The contribution of information technology to consumer welfare. Information Systems Research 7(3), 281-300.

BRYNJOLFSSON E and HITT L (1995) Information technology as a factor of production: the role of differences among firms. Economics of Innovation and New Technology 3(4), 183-200.

BRYNJOLFSSON E and HITT L (1996) Paradox lost? Firm-level evidence on the returns to information systems spending. Management Science 42(4), 541-558.

BRYNJOLFSSON E and HITT LM (1998) Beyond the productivity paradox. Communications of the ACM 41(8), 49-55.

BRYNJOLFSSON E and HITT LM (2000) Beyond computation: information technology, organizational transformation and business performance. Journal of Economic Perspectives 14(4), 23-48.

BRYNJOLFSSON E and HITT LM (2003) Computing productivity: firm-level evidence. Review of Economics and Statistics 85(4), 793-808.

BRYNJOLFSSON E, HITT LM and YANG S (2000) Intangible Assets: How the Interaction of Computers and Organizational Structure Affects Stock Market Valuations. MIT, Cambridge, MA, US.

BRYNJOLFSSON E, HITT LM and YANG SK (2002) Intangible assets: computers and organizational capital. Brookings Papers on Economic Activity (1), 137-198.

BRYNJOLFSSON E and YANG S (1996) Information technology and productivity: a review of the literature. In Advances in Computers (Zelkowitz MV, Ed.), Vol. 43, 179-215, Academic Press, San Diego, CA, US.

BRYNJOLFSSON E and YANG S (1999) The intangible costs and benefits of computer investments: evidence from the financial markets. In Proceedings of the Twentieth International Conference on Information Systems (PRABUDDHA D and DeGross Il, Eds). Association for Information Systems, Charlotte, North Carolina, USA, ICIS 1999, 13-15 December.

BYRD TA and TURNER DE (2000) Measuring the flexibility of information technology infrastructure: exploratory analysis of a construct. Journal of Management Information Systems 17(1), 167-208.

CALDEIRA MM and WARD JM (2003) Using resource-based theory to interpret the successful adoption and use of information systems and technology in manufacturing small and medium-sized enterprises. European Journal of Information Systems 12(2), 125-139.

CALLON M (1991) Techno-economic networks and irreversibility. In $A$ Sociology of Monsters? Essays on Power, Technology and Domination, Sociological Review Monograph (LAW J, Ed.), pp 132-161, Routledge, London.

CARR NG (2003) IT doesn't matter. Harvard Business Review 81(5), 41-49.

CASOLARO $L$ and GOBBI G (2007) Information technology and productivity changes in the banking industry. Economic Notes 36(1), 43-76.

CHAFFEY D and WOOD S (2005) Business Information Management Improving Performance Using Information Systems. Prentice Hall, Essex, England.

CHAN YE (2000) IT value: the great divide between qualitative and quantitative and individual and organizational measures. Journal of Management Information Systems 16(4), 225-261.

ChaRI MDR, DeVARAJ S and DAVID P (2008) The impact of information technology investments and diversification strategies on firm performance. Management Science 54(1), 224-234.

ChATFIELD AT and YetTON P (2000) Strategic payoff from EDI as a function of EDI embeddedness. Journal of Management Information Systems 16(4), 195-224.

ChatTeriee D, PACINI C and SAMBamurthy V (2002) The shareholder-wealth and trading-volume effects of information-technology infrastructure investments. Journal of Management Information Systems 19(2), 7-42.

ChATterJeE D, RIChardson VJ and ZMUD RW (2001) Examining the shareholder wealth effects of new $\mathrm{CIO}$ position announcements. MIS Quarterly 25(1), 43-70.

CHAU PYK, KUAN KKY and LIANG TP (2007) Research on IT value: what we have done in Asia and Europe. European Journal of Information Systems 16(3), 196-201.

CHEN SJ and HWANG CL (1991) Fuzzy Multiple Attribute Decision Making: Methods and Applications. Springer, Berlin, Germany.

CHEN YH and LIN WT (2009) Analyzing the relationships between information technology, inputs substitution and national characteristics based on CES stochastic frontier production models. International Journal of Production Economics 120(2), 552-569.

CHO W and SHAW MJ (2009) Does IT synergy matter in IT portfolio selection?. International Conference on Information Systems, Phoenix, Arizona, USA.

CHRISTENSEN HA and MONTGOMERY CA (1981) Corporate economic performance: diversification strategy versus market structure. Strategic Management Journal 2(4), 327-343.

CiBORRA CU and LANZARA GF (1994) Formative contexts and information technology: understanding the dynamics of innovation in organizations. Accounting, Management and Information Technologies 4(2), $61-86$

CLEMEN RT (1991) Making Hard Decisions: An Introduction to Decision Analysis. PWS-KENT, Boston, MA.

CLEMONS EK and KLEINDORFER PR (1992) An economic analysis of interorganizational information technology. Decision Support Systems 8(5), 431-446.

CLEMONS EK and Row MC (1991) Sustaining IT advantage - the role of structural differences. MIS Quarterly 15(3), 275-292.

CNSS (2006) National Information Assurance Glossary. Committee on National Security Systems [WWW document] http://www.cnss.gov/ Assets/pdf/cnssi_4009.pdf.

COHEN WM and LEVINTHAL DA (1990) Absorptive capacity: a new perspective on learning and innovation. Administrative Science Quarterly 35(1), 128-152.

CULNAN MJ, MCHUGH PJ and ZUBillaGa JI (2010) How large U.S. companies can use twitter and other social media to gain business value. MIS Quarterly Executive 9(4), 243-260.

DAFT RL (1978) Dual-core model of organizational innovation. Academy of Management Journal 21(2), 193-210.

DAS S, YAYLACICEGI U and MENON NM (2011) The effect of information technology investments in healthcare: a longitudinal study of its lag, duration, and economic value. IEEE Transactions on Engineering Management 58(1), 124-140.

DAVERN MJ and KAUFFMAN RJ (2000) Discovering potential and realizing value from information technology investments. Journal of Management Information Systems 16(4), 121-143. 
DAVERN MJ and WILKIN CL (2010) Towards an integrated view of IT value measurement. International Journal of Accounting Information Systems 11(1), 42-60.

DEDRICK J, GURBAXANI V and KRAEMER KL (2003) Information technology and economic performance: a critical review of the empirical evidence. ACM Computing Surveys 35(1), 1-28.

Dehning B, Pfeiffer GM and RiChardson VJ (2007a) Analysts' forecasts and investments in information technology. International Journal of Accounting Information Systems 7(3), 238-250.

DEHNING B and RICHARDSON VJ (2002) Returns on investments in information technology: a research synthesis. Journal of Information Systems 16(1), 7-30.

DEHNING B, RICHARDSON VJ, SMITH RE and ZMUD RW (2008) Using accounting-based performance measures to assess the business value of information technologies and systems. In Economics, Information Systems and Electronic Commerce Research II: Advanced Empirical Methodologies (KAUFFMAN RJ and TALLON PP, Eds), pp 135-154, ME Sharpe, Armonk, NY.

DEHNING B, RICHARDSON VJ, URBACZEWSKI A and WelLS JD (2004) Reexamining the value relevance of ecommerce initiatives. Journal of Management Information Systems 21(1), 57-84.

DEHNING B, RICHARDSON VJ and ZMUD RW (2003) The value relevance of announcements of transformational information technology investments. MIS Quarterly 27(4), 637-656.

DEHNING B, RICHARDSON VJ and ZMUD RW (2007b) The financial performance effects of IT-based supply chain management systems in manufacturing firms. Journal of Operations Management 25(4), 806-824.

DEHNING B and StRATOPOULOS T (2002) DuPont analysis of an IT-enabled competitive advantage. The International Journal of Accounting Information Systems 3(3), 165-176.

DEJARNETT L, LASKEY R and TRAINOR HE (2004) From the CIO point of view: the 'IT doesn't matter' debate. Communications of the Association for Information Systems 13(1), 443-455.

Dellarocas C, GAO G and Narayan R (2010) Are consumers more likely to contribute online reviews for hit or niche products? Journal of Management Information Systems 27(2), 127-157.

DELONE WH and MCLEAN ER (1992) Information systems success: the quest for the dependent variable. Information Systems Research 3(1), 60-95.

DELONE WH and MCLEAN ER (2003) The DeLone and McLean model of information systems success: a ten-year update. Journal of Management Information Systems 19(4), 9-30.

DELONE WH and MCLEAN ER (2004) Measuring e-commerce success: applying the DeLone \& McLean information systems success model. International Journal of Electronic Commerce 9(1), 31-47.

DERHAM R, CRAGG P and MORRISH S (2011) Creating value: an SME and social media. In Pacific Asia Conference on Information Systems, PACIS 2011 (SEDDON PB and GreGOR S, Eds), Queensland University of Technology. Quality Research in Pacific Asia, Brisbane, Queensland, Australia, 7-11 July.

DESANCTIS G and POOLE MS (1994) Capturing the complexity in advanced technology use: adaptive structuration theory. Organization Science 5(2), 121-147.

DEVARAJ S and KOHLI R (2000) Information technology payoff in the health-care industry: a longitudinal study. Journal of Management Information Systems 16(4), 41-67.

DEWAN S and KRAEMER KL (2000) Information technology and productivity: evidence from country-level data. Management Science 46(4), 548-562.

DEWAN S and MIN CK (1997) The substitution of information technology for other factors of production: a firm level analysis. Management Science 43(12), 1660-1675.

DEWAN S and REN F (2007) Risk and return of information technology initiatives: evidence from electronic commerce announcements. Information Systems Research 18(4), 370-394.

DEWAN S and REN F (2011) Information technology and firm boundaries: impact on firm risk and return performance. Information Systems Research 22(2), 369-388.

DEWAN S, SHI C and GURBAXANI V (2007) Investigating the risk-return relationship of information technology investment: firm-level empirical analysis. Management Science 53(12), 1829-1842.
DIERICKX I and COOL K (1989) Asset stock accumulation and sustainability of competitive advantage. Management Science 35(12), 1504-1511.

DimagGio PJ (1995) Comments on 'What Theory Is Not'. Administrative Science Quarterly 40(3), 391-397.

DONG S, XU SX and ZHU KX (2009) Information technology in supply chains: the value of IT-enabled resources under competition. Information Systems Research 20(1), 18-32.

Dos SANTOS BL, PefFers KG and MAUer DC (1993) The impact of information technology investment announcements on the market value of the firm. Information Systems Research 4(1), 1-23.

DOS SANTOS BL, RAJAGOPALAN S, RAO RH and YANG B (1996) Information technology investments and firm performance. In Proceedings of the Americas Conference on Information Systems, (CAREY JM, Ed.), Arizona, USA, Phoenix, 16-18 August.

DRUCKER P (1988) The coming of the new organization. Harvard Business Review 66(1), 45-53.

DuBIN R (1978) Theory Development. New York Free Press, New York, NY, US.

DYLLICK T and HOCKERTS K (2002) Beyond the business case for corporate sustainability. Business Strategy and the Environment 11(2), 130-141.

ENGELBERT H (1991) Scientific information as an economic category. In The Economics of Information Systems and Software (VERYARD R, Ed.), pp 31-43, Butterworth-Heinemann, Oxford.

FARJOUN M (1998) The independent and joint effects of the skill and physical bases of relatedness. Strategic Management Journal 19(7), 611-630.

FEENY DF and IVES B (1990) In search of sustainability: reaping long-term advantage from investments in information technology. Journal of Management Information Systems 7(1), 27-46.

FINK L (2011) How do IT capabilities create strategic value? Toward greater integration of insights from reductionistic and holistic approaches. European Journal of Information Systems 20(1), 16-33.

FISHBURN PC (1970) Utility Theory for Decision Making. Robert E. Krieger Publishing Co., Huntington, NY.

FLOYD SW and WoOLDRIDGE B (1990) Path analysis of the relationship between competitive strategy, information technology, and financial performance. Journal of Management Information Systems 7(1), 47-64.

FULK J and DESANCTIS G (1995) Electronic communication and changing organizational forms. Organization Science 6(4), 337-349.

GARUD R, KUMARASWAMY A and SAMBAMURTHY V (2006) Emergent by design: performance and transformation at Infosys technologies. Organization Science 17(2), 277-286.

GRANT RM (1996) Toward a knowledge based theory of the firm. Strategic Management Journal 17(Winter Special Issue), 109-122.

Gregor S, Martin M, Fernandez W, Stern S and Vitale M (2006) The transformational dimension in the realization of business value from information technology. The Journal of Strategic Information Systems 15(3), 249-270.

GURBAXANI V and WHANG S (1991) The impact of information systems on organizations and markets. Communications of the ACM 34(1), 59-73.

HAN K, CHANG YB and HAHN J (2011) Information technology spillover and productivity: the role of information technology intensity and competition. Journal of Management Information Systems 28(1), 115-145.

HANNU HSS (2008) Analysing business losses caused by information systems risk: a business process analysis approach. Journal of Information Technology 23(3), 185-202.

HARRIS EH and KATZ JL (1991) Organizational performance and information technology investment intensity in the insurance industry. Organizational Science 2(3), 263-295.

HAYES DC, HUNTON JE and RECK JL (2001) Market reaction to ERP implementation announcements. Journal of Information Systems 15(1), 3-18.

Hinz O, Skiera B, Barrot C and BeCker JU (2012) Seeding strategies for viral marketing: an empirical comparison. Journal of Marketing 75(6), 55-71.

HITT L and BRYNJOLFSSON E (1994) The three faces of IT value: theory and evidence. In Proceedings of the Fifteenth International Conference on Information Systems (DEGross JI, HufF SL, Munro M, Eds), pp 263-277, Association for Information Systems, Vancouver, British Columbia, Canada. 
HITT LM and BRYNJOLFSSON E (1996) Productivity, business profitability, and consumer surplus: three different measures of information technology value. MIS Quarterly 20(2), 121-142.

Ho JLY, WU A and XU SX (2011) Corporate governance and returns on information technology investment: evidence from an emerging market. Strategic Management Journal 32(6), 595-623.

HOOGEVEen D and OpPeLLAND HJ (2002) A socio political model of the relationship between IT investments and business performance. 35th Hawaii International Conference on System Sciences, IEEE Computer Society Press, $\mathrm{p} 259 \mathrm{~b}$.

HSIEH JJP-A, RAI A and XU SX (2011) Extracting business value from IT: a sensemaking perspective of post-adoptive use. Management Science 57(11), 2018-2039.

IM KS, DOW KE and GROVER V (2001) A reexamination of IT investment and the market value of the firm - an event study methodology. Information Systems Research 12(1), 103-117.

IRANI Z (2002) Information systems evaluation - navigating through the problem domain. Information \& Management 40(1), 11-24.

IRANI Z and LOVE PED (2001) The propagation of technology management taxonomies for evaluating investments in information systems. Journal of Management Information Systems 17(3), 159-175.

IRANI Z and LOVE PED (2002) Developing a frame of reference for ex-ante IT/IS investment evaluation. European Journal of Information Systems 11(1), 74-82.

ITAA (1996) Help Wanted: The IT Workforce Gap at the Dawn of the New Century. The Information Technology Association of America, Arlington, VA.

JAIN A (2005) Performance paradox, information technology investments and administrative performance in the case of the 50 US state governments. International Conference on Information Systems, pp. $389-400$.

JARVENPAA SL and LeIDNER DE (1998) An information company in Mexico: extending the resource-based view of the firm to a developing country context. Information Systems Research 9(4), 342-361.

JELASSI T and FIGON O (1994) Competing through EDI at Brun Passot: achievements in France and ambitions for the single European market. MIS Quarterly 18(4), 337-352.

JORGENSEN DW (2001) Information technology and the U.S. economy (Presidential address to the American Economic Association). American Economic Review 91(1), 1-32.

JORGENSON DW and STIROH KJ (1995) Computers and growth. Economics of Innovation and New Technology 3(3-4), 295-316.

JORGENSON DW and STIROH KJ (1999) Information technology and growth. American Economic Review 89(2), 109-115.

JORGENSON DW and STIROH KJ (2000) Raising the speed limit: U.S. economic growth in the information age. Brookings Papers on Economic Activity 1(1), 125-211.

KANE GC and ALAVI M (2007) Information technology and organizational learning: an investigation of exploration and exploitation processes. Organization Science 18(5), 796-812.

KARIMI I, SOMERS TM and BHATTACHERIEE A (2007) The role of information systems resources in ERP capability building and business process outcomes. Journal of Management Information Systems 24(2), 221-260.

KAUFFMAN RJ and WEILL P (1989) An evaluative framework for research on the performance effects of information technology investment. In Proceedings of the Tenth International Conference on Information Systems, pp 377-388, Association for Information Systems, ACM, Boston, MA.

KELLEY MR (1994) Productivity and information technology - the elusive connection. Management Science 40(11), 1406-1425.

KIM D, CaVusGiL ST and CALANTONE RJ (2006) Information system innovations and supply chain management: channel relationships and firm performance. Journal of the Academy of Marketing Science 34(1), 40-54.

KIM G, SHIN B, KIM KK and LEE HG (2011) IT capabilities, process-oriented dynamic capabilities, and firm financial performance. Journal of the Association for Information Systems 12(7), 487-517.

KIM JK, XIANG JY and LEE S (2009) The impact of IT investment on firm performance in China: an empirical investigation of the Chinese electronics industry. Technological Forecasting and Social Change, to appear 76(5), 678-687.
KIM K and MITHAS S (2011) How does bond market view IT investments of firms? An empirical evidence of bond ratings and yield spreads. In Proceedings of the International Conference on Information Systems, ICIS 2011 (Galletta DF and Liang T-P, Eds), Shanghai, China, Association for Information Systems, 4-7 December.

KO M and BRYSON K-M (2002) A regression tree based exploration of the impact of information technology investments on firm level productivity. In Proceedings of the 10th European Conference on Information Systems, ECIS 2002 (WRYCZA S, Ed.), pp 506-517, Gdansk, Poland, Information Systems and the Future of the Digital Economy, 6-8 June.

KO M and OSEI-BRYSON KM (2004) Using regression splines to assess the impact of information technology investments on productivity in the health care industry. Information Systems Journal 14(1), 43-63.

KOHLI R and GROVER V (2008) Business value of IT: an essay on expanding research directions to keep up with the times. Journal of the Association for Information Systems 9(1), 23-39.

KRAeMER KL, DeDRICK J and YAMASHIRO S (2000) Refining and extending the business model with information technology: Dell Computer Corporation. The Information Society 16(1), 5-21.

LATOUR B (1991) Technology is society made durable. In A Sociology of Monsters? Essays on Power, Technology and Domination, Sociological Review Monograph (LaW I, Ed.), pp 103-131, Routledge, London.

LAUDON KC and LAUDON JP (2005) Essentials of Management Information Systems - Managing the Digital Firm. Pearson, Upper Saddle River, NI.

LeE AHI, Chen WC and CHANG CJ (2008) A fuzzy AHP and BSC approach for evaluating performance of IT department in the manufacturing industry in Taiwan. Expert Systems with Applications 34(1), 96-107.

LEE H, YU J and KIM H (2004) An empirical study on the integrated performance model for the effect of information technology investments. In Proceedings of the Eight Pacific Asia Conference on Information Systems. China Association for Information Systems, Shanghai.

LeE O-K, LIM KH, SambamuRThy $V$ and WeI KK (2007) IT-enabled organizational agility and firms' sustainable competitive advantage. In Proceedings of the International Conference on Information Systems, Association for Information Systems, ICIS 2007, Montreal, Quebec, Canada, 9-12 December.

LEE S, XIANG JY and KIM JK (2011) Information technology and productivity: empirical evidence from the Chinese electronics industry. Information \& Management 48(2/3), 79-87.

LEONARDI PM (2007) Activating the informational capabilities of information technology for organizational change. Organization Science 18(5), 813-831.

LI MF and YE LR (1999) Information technology and firm performance: linking with environmental, strategic and managerial contexts. Information \& Management 35(1), 43-51.

LICHTENBERG FR (1995) The output contributions of computer equipment and personnel: a firm-level analysis. Economics of Innovation and New Technology 3(4), 201-217.

LIM JH, RICHARDSON VJ and ROBERTS TL (2004) Information technology investment and firm performance - a meta-analysis. In Proceedings of the 37th Hawaii International Conference on System Sciences, IEEE Computer Society, Big Island, HI, USA, 5-8 January 2004.

LIN WT (2009) The business value of information technology as measured by technical efficiency: evidence from country-level data. Decision Support Systems 46(4), 865-874.

LIN WT and CHIANG C-Y (2011) The impacts of country characteristics upon the value of information technology as measured by productive efficiency. International Journal of Production Economics 132(1), 13-33.

LIN WT and SHAO BBM (2006a) Assessing the input effect on productive efficiency in production systems the value of information technology capital. International Journal of Production Research 44(9), 1799-1819.

LIN WT and SHAO BBM (2006b) The business value of information technology and inputs substitution: the productivity paradox revisited. Decision Support Systems 42(2), 493-507.

loos P, Nebel W, Gómez JM, Hasan H, Watson RT, Vom Brocke I and SEIDEL $S$ and 3(4) JR (2011) Green IT: a matter of business and information systems engineering? Business \& Information Systems Engineering 3(4), 245-252.

LOVEMAN GW (1994) An assessment of the productivity impact of information technologies. In Information Technology and the Corporation of the 1990s: Research Studies (ALLEN TI and SCOTT-MORTON MS, Eds), pp 84-110, Oxford University Press, Oxford, UK. 
MAHMOOD MA and MANN GJ (1993) Measuring the organizational impact of information technology investment: an exploratory study. Journal of Management Information Systems 10(1), 97-122.

MAHMOOD MA and MANN GJ (2005) Information technology investments and organizational productivity and performance: an empirical investigation. Journal of Organizational Computing and Electronic Commerce 15(3), 185-202.

MARKUS ML and ROBEY D (1988) Information technology and organizational change: causal structure in theory and research. Management Science 34(5), 583-598.

MARKUS ML and ROBEY D (2004) Why stuff happens: explaining the unintended consequences of using information technology. In The Past and Future of Information Systems (MoRTen ThANNIng Vendelo KVA, Ed.), pp 61-93, Elsevier Butterworth-Heinemann, Amsterdam, The Netherlands.

MARTHANDAN G and TANG CM (2010) Information systems evaluation: an ongoing measure. International Journal of Business Information Systems 6(3), 336-353.

MARTIN-Oliver A and SAlas-Fumas $V$ (2008) The output and profit contribution of information technology and advertising investments in banks. Journal of Financial Intermediation 17(2), 229-255.

MATA FJ, FUerST WL and BARNEY JB (1995) Information technology and sustained competitive advantage: a resource-based analysis. MIS Quarterly 19(4), 487-505.

MCAFEE A (2002) The impact of enterprise information technology adoption on operational performance - an empirical investigation. Production and Operations Management 11(1), 33-53.

MCFARLAN FW (1981) Portfolio approach to information systems. Harvard Business Review 59(5), 142-150.

Melville N, Gurbaxani V and Kraemer K (2007) The productivity impact of information technology across competitive regimes: the role of industry concentration and dynamism. Decision Support Systems 43(1), 229-242.

Melville N, Kraemer K and Gurbaxani V (2004) Review: information technology and organizational performance: an integrative model of IT business value. MIS Quarterly 28(2), 283-322.

MENON NM, LEE B and ELDENBURG L (2000) Productivity of information systems in the healthcare industry. Information Systems Research 11(1), 83-92.

MEYER JW and ROWAN B (1991) Institutionalized organizations: formal structure as myth and ceremony. In The New Institutionalism in Organizational Analysis (POWELL WW and DIMAGGIO PJ, Eds), Chicago University Press, Chicago, IL.

MILGROM P and ROBERTS I (1995) Complementarities and fit strategy, structure and organizational change in manufacturing. Journal of Accounting and Economics 19(2-3), 179-208.

MILLER DJ (2004) Firms' technological resources and the performance effects of diversification: a longitudinal study. Strategic Management Journal 25(11), 1097-1119.

Mithas S, RAMASUBbu N and SAMbamuRTHY V (2011) How information management capability influences firm performance. MIS Quarterly 35(1), 237-256.

MOONey I, Gurbaxani $V$ and Kraemer K (1995) A process oriented framework for assessing the business value of information technology. In Proceedings of the Sixteenth International Conference on Information Systems (Ariav G, Beath CM, Degross Jl, Hoyer R and Kemerer CF, Eds), pp 17-27, Association for Information Systems, Amsterdam, The Netherlands, 10-13 December.

MUKHOPADHYAY T, KeKRE $S$ and KalATHUR S (1995) Business value of information technology: a study of electronic data interchange. MIS Quarterly 19(2), 137-156.

MUTCH A (2010) Technology, organization, and structure - a morphogenetic approach. Organization Science 21(2), 507-520.

NAIR M (2011) Understanding and measuring the value of social media. Journal of Corporate Accounting \& Finance 22(3), 45-51.

NeIROTTI P and PAOLUCCI E (2007) Assessing the strategic value of information technology: an analysis on the insurance sector. Information \& Management 44(6), 568-582.

NELSON R and WINTER S (1982) An Evolutionary Theory of Economic Change. Harvard University Press, Cambridge, MA.

NELSON RR (2007) IT project management: infamous failures, classic mistakes, and best practices. MIS Quarterly Executive 6(2), 67-78.
NEWMAN M and SABHERWAL R (1991) Information systems development: four process scenarios with case studies. Journal of Information Systems 5(1), 84-101.

OLINER SD and SICHEL DE (2000) The resurgence of growth in the late 1990s: is information technology the story? Journal of Economic Perspectives 14(4), 3-22.

ORDANINI A and RUBERA G (2010) How does the application of an IT service innovation affect firm performance? A theoretical framework and empirical analysis on e-commerce. Information \& Management 47(1), 60-67.

ORLIKOWSKI WJ (1992) The duality of technology: rethinking the concept of technology in organizations. Organization Science 3(3), 398-427.

ORLIKOWSKI WJ (1996) Improvising organizational transformation over time: a situated change perspective. Information Systems Research 7(1), 63-92.

ORLIKOWSKI WJ and IACONO CS (2001) Desperately seeking the 'IT' in IT research. A call to theorizing the IT artifact. Information Systems Research 12(2), 121-134.

ORLIKOWSKI WJ and WALSHAM G (Eds) (1996) Information Technology and Changes in Organizational Work. Chapman \& Hall, London.

Oz E (2005) Information technology productivity: in search of a definite observation. Information \& Management 42(6), 789-798.

PALEPU K (1985) Diversification strategy, profit performance and the entropy measure. Strategic Management Journal 6(3), 239-255.

Paré G, Bourdeau S, Marsan J, Nach H and Shuraida S (2008) Re-examining the causal structure of information technology impact research. European Journal of Information Systems 17(4), 403-416.

PESLAK AR (2003) A firm level study of information technology productivity using financial and market based measures. Journal of Computer Information Systems 43(4), 72-80.

PfefFER J and SALANCIK GR (1978) The External Control of Organizations: A Resource Dependence Perspective. Harper and Row, New York.

PICCOLI G and IVES B (2005) Review: IT-dependent strategic initiatives and sustained competitive advantage: a review and synthesis of the literature. MIS Quarterly 29(4), 747-776.

PINSONNEAULT A and KRAEMER KL (2002) Exploring the role of information technology in organizational downsizing: a tale of two American cities. Organization Science 13(2), 191-208.

POON SK and DAVIS JG (2003) Estimating the impact of information technology investments on Australian productivity. In Proceedings of the Australasian Conference on Information Systems (ANG I, KNIGHT S-A, Eds), Edith Cowan University, Perth, Western Australia, 26-28 November.

POON SK, DAVIS JG and CHOI B (2009) Augmenting productivity analysis with data mining: an application on IT business value. Expert Systems with Applications 36(2), 2213-2224.

POSTON R and GRABSKI S (2000) The impact of enterprise resource planning systems on firm performance. In Proceedings of the TwentyFirst International Conference on Information Systems, ICIS 2000 (ANG S, Krcmar H, Orlikowski WJ, Weill P and Degross Jl, Eds), pp 479-493, Brisbane, Australia, 10-13 December.

POWELL TC and DeNT-Micallef A (1997) Information technology as competitive advantage: the role of human, business, and technology resources. Strategic Management Journal 18(5), 375-405.

POWELL W (1990) Neither market nor hierarchy: network forms of organization. Research on Organizational Behavior 12, 295-336.

RAGHUPATHI W (2007) Corporate governance of IT: a framework for development. Communications of the ACM 50(8), 94-99.

Rai A, Patnayakuni R and Patnayakuni N (1997) Technology investment and business performance. Communications of the ACM 40(7), 89-97.

RAI A and TANG X (2010) Leveraging IT capabilities and competitive process capabilities for the management of interorganizational relationship portfolios. Information Systems Research 21(3), 516-542.

RAINER K and MILLER M (2005) Examining differences across journal rankings. Communications of the ACM 48(2), 91-94.

Ramirez R, Melville N and LaWler E (2010) Information technology infrastructure, organizational process redesign, and business value: an empirical analysis. Decision Support Systems 49(4), 417-429.

RAVICHANDRAN T and LERTWONGSATIEN C (2005) Effect of information systems resources and capabilities on firm performance: a resourcebased perspective. Journal of Management Information Systems 21(4), 237-276. 
ReICHeLD F and SCHeFTER P (2000) E-loyalty: your secret weapon on the web. Harvard Business Review 78(4), 105-113.

RICHARDSON VJ and ZMUD RW (2002) The value relevance of information technology investment announcements: incorporating industry strategic IT role. 35th Annual Hawaii International Conference on System Sciences 8, 1-10.

ROACH SS (1987) America's Technology Dilemma: A Profile of the Information Economy. Morgan Stanley, New York, NY, USA.

ROACH SS (1991) Services under siege: the restructuring imperative. Harvard Business Review 39(2), 82-92.

ROBINS JA and WIERSEMA M (1995) A resource-based approach to the multibusiness firm. Strategic Management Journal 16(4), 277-299.

ROCKART JF (1979) Chief executives define their own data needs. Harvard Business Review 57(2), 81-93.

Ross JW, BEATH CM and GoOdhuE DL (1996) Develop long term competitiveness through IT assets. Sloan Management Review 38(1), $31-45$.

ROWE F (1994) Data network productivity and competitive behavior: the case of the French commercial banks. Technological Forecasting and Social Change 46(1), 29-44.

ROZTOCKI N and WEISTROFFER HR (2008) Event studies in information systems research: a review. In Proceedings of the Americas Conference on Information Systems, 14th Americas Conference on Information Systems, AMCIS 2008, Toronto, Ontario, Canada (BenBASAT I and MonTAZEMI AR, Eds), Association for Information Systems, Toronto, Canada, 14-17 August.

RUMELT RP (1982) Diversification strategy and profitability. Strategic Management Journal 3(4), 359-369.

SAMBAMURTHY V and ZMUD RW (2000) Research commentary: the organizing logic for an enterprise's IT activities in the digital era - a prognosis of practice and a call for research. Information Systems Research 11(2), 105-114.

SANTHANAM R and HARTONO E (2003) Issues in linking information technology capability to firm performance. MIS Quarterly 27(1), 125-153.

SCHNEBERGER $S$ and WADE M (2010) Theories used in IS research Wik http://www.fsc.yorku.ca/york/istheory/wiki/index.php/Main_Page.

SCHRAGE M (2003) How IT Can Differentiate Your Business from the Competition. $\mathrm{ClO}$, Framingham, MA, USA

SCHWARZ A and HIRSCHHEIM R (2003) An extended platform logic perspective of IT governance: managing perceptions and activities of IT. The Journal of Strategic Information Systems 12(2), 129-166.

SEDDON PB (1997) A respecification and extension of the DeLone and McLean model of IS success. Information Systems Research 8(3), 240-253.

SCHRYEN G (2010a) An analysis of literature reviews on IS business value: how deficiencies in methodology and theory use resulted in limited effectiveness. In Proceedings of the First Scandinavian Conference on Information Systems (SCIS) (KAUTZ $\mathrm{K}$ and NIELSEN PA, Eds), Rebild, Denmark, 20-22 August, Lecture Notes in Business Information Processing 60, Springer.

SCHRYEN G and BODENSTEINC (2010b) A decision-theoretic foundation of IS business value research. In Proceedings of the 18th European Conference on Information Systems (ECIS 2010) (ALEXANDER PM, TURPIN $M$ and VAN DeVEnTER JP, Eds), Pretoria, South Africa, 7-9 June.

SCHRYEN G (2011) Seeking the value in IS business value Research - an agenda for investigating synergies between socio-organizational change, IS capabilities change, and IS innovation. In Proceedings of the 19th European Conference on Information Systems (ECIS 2011) (TUunainen VK, Rossi M and Nandhakumar J, Eds), Helsinki, Finland, 9-11 June.

Seddon PB, PatnayakunI $R$ and Bowtell $M$ (1999) Dimensions of information systems success. Communications of the AIS 2(3), 1-61.

SeNADHEERA V, WARREN M and LeitCH S (2011) A study into how Australian banks use social media. In Proceedings of the Pacific Asia Conference on Information Systems, PACIS 2011 (SEDDON PB and GreGor S, Eds). Queensland University of Technology. Pacific Asia Conference on Information Systems, Quality Research in Pacific Asia, Brisbane, Queensland, Australia, 7-11 July.

SETHI V and KING WR (1994) Development of measures to assess the extent to which an information technology application provides competitive advantage. Management Science 40(12), 1601-1627.
SHIN N (1997) The impact of information technology on coordination costs: implications for firm productivity. In Proceedings of the Eighteenth International Conference on Information Systems (DEGROSS JI and KUMAR K, Eds), pp 133-146, Association for Information Systems, Atlanta, Georgia, USA, 15-17 December.

SHIN N (2006) The impact of information technology on the financial performance of diversified firms. Decision Support Systems 41(4), 698-707.

SIRCAR S, TURNBOW JL and BORDOLOI B (1998) The impact of information technology investments on firm performance: a review of the literature. The Journal of Engineering Valuation and Cost Analysis 1(3), 171-181.

SIRCAR S, TURNBOW JL and BORDOLOI B (2000) A framework for assessing the relationship between information technology investments and firm performance. Journal of Management Information Systems 16(4), 69-97.

SOH C and MARKUS ML (1995) How IT creates business value: a process theory synthesis. In Proceedings of the Sixteenth International Conference on Information Systems (Ariav G, BeAth CM, DeGross JI, Hoyer R and Kemerer CF, Eds), pp 29-41, Association for Information Systems, Amsterdam, The Netherlands, 10-13 December.

STAEHR L (2010) Understanding the role of managerial agency in achieving business benefits from ERP systems. Information Systems Journal 20(3), 213-238.

STIROH KJ (2002) Information technology and the US productivity revival: what do the industry data say? American Economic Review 92(5), 1559-1576.

StRatopoulos T and DeHNING B (2000) Does successful investment in information technology solve the productivity paradox? Information \& Management 38(2), 103-117.

SUBRAMANI $M$ and WALDEN E (2001) The impact of e-commerce announcements on the market value of firms. Information Systems Research 12(2), 135-154.

SUTTON RI and STAW BM (1995) What theory is not. Administrative Science Quarterly 40(3), 371-384.

SWIERCZEK FW and SHRESTHA PK (2003) Information technology and productivity: a comparison of Japanese and Asia-Pacific banks. The Journal of High Technology Management Research 14(2), 269-288.

SYLLA C and WEN HJ (2002) A conceptual framework for evaluation of information technology investments. International Journal of Technology Management 24(2-3), 236-261.

TAllon PP, Kraemer KL and Gurbaxani V (2000) Executives' perceptions of the business value of information technology: a processoriented approach. Journal of Management Information Systems 16(4), 145-173.

TAM KY (1998) The impact of information technology investments on firm performance and evaluation: evidence from newly industrialized economies. Information Systems Research 9(1), 85-98.

TAMBE P, HITT L and BRYNJOLFSSON E (2012) The extroverted firm: how external information practices affect innovation and productivity. Management Science 58(5), 843-859.

TAN BCC, PAN SL and HACKNEY R (2010) The strategic implications of web technologies: a process model of how web technologies enhance organizational performance. IEEE Transactions on Engineering Management 57(2), 181-197.

TANRIVERDI $\mathrm{H}$ and VENKATRAMAN N (2005) Knowledge relatedness and the performance of multibusiness firms. Strategic Management Journal 26(2), 97-119.

THATCHER ME and OLIVER JR (2001) The impact of technology investments on a firm's production efficiency, product quality, and productivity. Journal of Management Information Systems 18(2), 17-45.

THATCHER ME and PINGRY DE (2004a) An economic model of product quality and IT value. Information Systems Research 15(3), 268-286.

THATCHER ME and PINGRY DE (2004b) Understanding the business value of information technology investments: theoretical evidence from alternative market and cost structures. Journal of Management Information Systems 21(2), 61-85.

THATCHER ME and PINGRY DE (2007) Modeling the IT value paradox. Communications of the ACM 50(8), 41-45 
THOUIN M, HOFFMAN JJ and FORD EW (2008) The effect of information technology investment on firm-level performance in the health care industry. Health Care Management Review 33(1), 60-68.

VENKATRAMAN N (1994) IT-enabled business transformation - from automation to business scope redefinition. Sloan Management Review 35(2), 73-87

ViCKerY SK, Droge C, Setia P and Sambamurthy V (2010) Supply chain information technologies and organisational initiatives: complementary versus independent effects on agility and firm performance. International Journal of Production Research 48(23), 7025-7042.

WADE M and HULLAND J (2004) Review: the resource-based view and information systems research: review, extension, and suggestions for future research. MIS Quarterly 28(1), 107-142.

WAN Z, FANG $Y$ and WADE M (2007) The ten-year odyssey of the IS productivity paradox - a citation analysis (1996-2006). In Proceedings of the Americas Conference on Information Systems. (HOXMEIER JA, HAYNE S, Eds), Keystone, Colorado.

WARD JM (1990) A portfolio approach to evaluating information systems investments and setting priorities. Journal of Information Technology 5(4), 222-231.

WATSON RT, BOUdREAU M-C and CHEN AJW (2010) Information systems and environmentally sustainable development: energy informatics and new directions for the IS community. MIS Quarterly 34(1), 23-38.

WEBSTER J and WATSON RT (2002) Analyzing the past to prepare for the future: writing a literature review. MIS Quarterly 26(2), XIII-XXIII.

WEILL $P$ (1992) The relationship between investment in information technology and firm performance: a study of the valve manufacturing sector. Information Systems Research 3(4), 307-333.

WEILL P and BROADBENT M (1998) Levering the New Infrastructure: How Market Leaders Capitalize on Information Technology. Harvard Business School Press, Cambridge, MA.

WEILL $P$ and OLSON M (1989) Managing investment in information technology: mini case examples and implications. MIS Quarterly 13(1), 3-18.

Weitzel T, ECKHARDT A and LAUMER S (2009) A framework for recruiting IT talent: lessons from Siemens. MIS Quarterly Executive 8(4), 123-137.
WERNERFELT B (1984) A resource-based view of the firm. Strategic Management Journal 5(2), 171-180.

WEST LA and COURTNEY JF (1993) The information problems in organizations - a research model for the value of information and information systems. Decision Sciences 24(2), 229-251.

WHETTEN DA (1989) What constitutes a theoretical contribution? Academy of Management Review 14(4), 490-495.

Whittington R, Pettigrew A, Peck S, Fenton E and Conyon M (1999) Change and complementarities in the new competitive landscape: a European panel study, 1992-1996. Organization Science 10(5), 583-600.

WHYTE J (2010) Taking time to understand: articulating relationships between technologies and organizations. In Technology and Organization: Essays in Honour of Joan Woodward (PhILLIPS N, SEWELL G and Griffiths D, Eds), pp 217-236, Emerald Group Publishing Limited.

WILLIAMS ML and FROLICK MN (2001) The evolution of EDI for competitive advantage: the FedEx case. Information Systems Management 18(2), 47-53.

WISEMAN D (1992) Information economics: a practical approach to valuing information systems. Journal of Information Technology 7(3), 169.

ZAMMUTO RF, GRIFFITH TL, MAJCHRZAK A, DOUGHERTY DJ and FARAJ S (2007) Information technology and the changing fabric of organization. Organization Science 18(5), 749-762.

ZHANG MJ (2005) Information systems, strategic flexibility and firm performance: an empirical investigation. Journal of Engineering and Technology Management 22(3), 163-184.

ZHANG MJ and LADO AA (2001) Information systems and competitive advantage: a competency-based view. Technovation 21(3), 147-156.

ZHU K and KRAEMER K (2005) Post-adoption variations in usage and value of e-business by organizations: cross-country evidence from the retail industry. Information Systems Research 16(1), 61-84.

ZHU K, KRAEMER KL, XU S and DeDRICK J (2004) Information technology payoff in e-business environments: an international perspective on value creation of e-business in the financial services industry. Journal of Management Information Systems 21(1), 17-54. 


\section{Appendix A}

\section{Statistics on IS business value papers published}

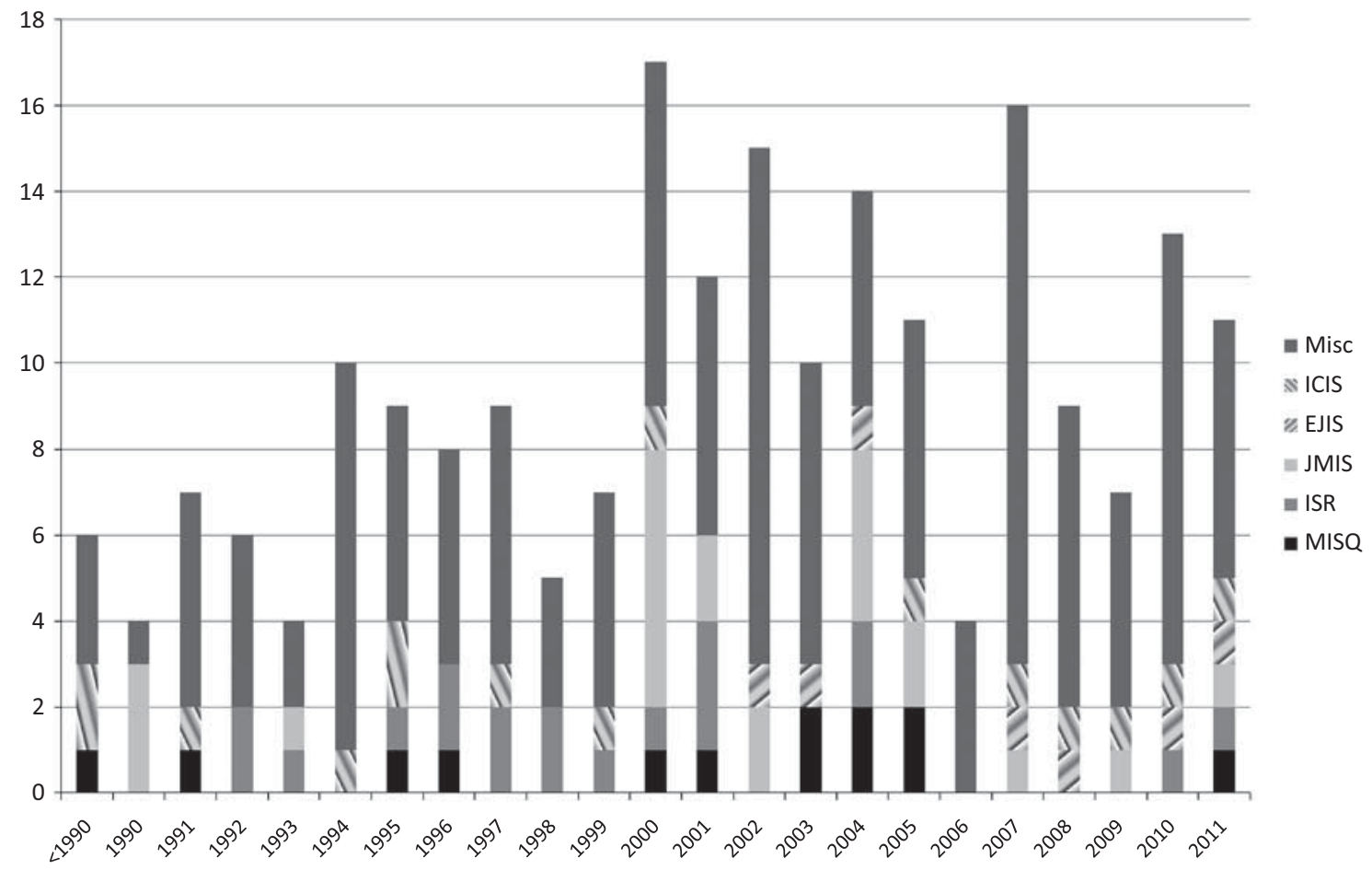

Figure A1 Number of IS business value papers published in renowned academic outlets. Note: We only considered papers where the primary focus lies on 'IS business value'.

\section{Appendix B}

\section{Identifying relevant literature}

In order to identify relevant literature, we followed the theoretical suggestions of Webster \& Watson (2002, p. xvi) and the practical procedure applied by Melville et al (2004) in their literature review. Overall, the process of identifying relevant literature consisted of four phases, which took more than 1 year to complete.

1. With the help of a student research assistant, we performed a title search in pertinent journal databases, namely Business Source Premier, MLA International Bibliography, EconLit, ScienceDirect, IEEE Xplore, The ACM Digital Library and Web of Science. The logical search string was: ('IT' OR 'information technology' OR 'IS' OR 'information systems') AND ('value' OR 'investment' OR 'productivity' OR 'competitive' OR 'performance' OR 'measurement' OR 'evaluation' OR 'profit' OR 'efficiency'). We did not limit our search to any specific time period. The last update of our search was conducted on 13 January 2012. In order to assure that no studies published in one of the most important IS journals were overlooked, we also scanned the table of contents in the following journals (the time period under consideration was January 1995 until December 2011):

(a) MIS Quarterly, Communications of the ACM, Information Systems Research, Management Science, and Journal of Management Information Systems: These journals were classified as the five leading journals in the latest MIS journal ranking (Rainer \& Miller, 2005).

(b) European Journal of Information Systems, Information Systems Journal and Journal of AIS: These journals are included in the more recent AIS list entitled 'Senior Scholars' Basket of Journals' (http://home.aisnet.org/displaycommon.cfm? an $=1$ \&subarticlenbr $=346$ ).

(c) Academy of Management Review, ACM Transactions on Information Systems, American Economic Review, 
Organization Science: Following references provided in the literature and by the reviewers and the editor of this paper, we found these journals appropriate candidates for containing valuable articles on IS business value. However, this selection mirrors the subjective opinion of the author.

2. We scanned the references of literature reviews that were identified during phase 1 . This procedure also allowed us to identify further literature reviews. The procedure was iterated until no further review was found. At the end of phase 2, we identified more than 400 research papers, including 20 literature reviews.

3. With the help of a student research assistant, we scanned the abstracts of these research papers and excluded those papers that did not seem to be related to the investigation of IS business value or that did not meet academic standards. In some cases it was also necessary to investigate the body of the paper at this stage. At the end of phase 3, we identified 327 research papers related to the economic value of IS.

4. In phase 4 , we analysed the body of these papers regarding their research questions, methodology and research models, and characteristics. From this list, we removed those empirical papers, which either did not describe their research model or which used a considerably small sample. The remaining articles are included in this study. 